\title{
A Research Synthesis Using Instrumental Learning Trajectories: Knowing How and Knowing Why
}

\author{
Dr. Stavroula Patsiomitou* \\ Ph.D., Department of Primary Education, University of Ioannina \\ MEd, Department of Mathematics, National and Kapodistrian University of Athens, Greece \\ *E-mail:spatsiom@gmail.com
}

\begin{abstract}
In the current study the theoretical notion of instrumental learning path or trajectory is analyzed through examples based on a research synthesis. I point out the role of instrumental decoding in a static or dynamic environment, and how the competence of the participants (students -researcher/ teacher) can influence the holistic result of the learning process by creating interdependencies/intra-dependencies during the construction of instrumental learning trajectories. Instrumental trajectories are not just construction instructions, or a set of information which provides the properties of the figure as the figure is constructed. Instrumental trajectories can show us the interdependencies/intra-dependencies that exist or can be created between different tools. Dynamic Geometry allows for the creation of interdependencies and intra-dependencies between mathematical objects, diagrams and tools. In the sections that follow, I shall present three examples of instrumental learning trajectories, in which the interdependencies among the tools and meanings are analyzed. My aim is to combine and synthesize different primary qualitative research studies and make their results more generalizable.
\end{abstract}

Keywords: instrumental decoding, interdependencies/intra-dependencies, instrumental learning trajectories

DOI: $10.7176 / \mathrm{IKM} / 11-3-02$

Publication date: April $30^{\text {th }} 2021$

\section{What are instrumental learning paths/trajectories?}

According to Evangelos Stamatis (1957) the creation of Geometry as a science is exclusively the work of the Greek spirit. The "Elements" were created in around 300BC by the youngest member of Plato's Academy, Euclid. When asked by King Ptolemy if there was a quicker or shorter path (an "atrapos" in Greek) to learn Geometry, Euclid replied that there was no "royal path" (royal atrapos) (Stamatis, 1957, p. 14). Dynamic geometry environments [for example: Geometer's Sketchpad (Jackiw, 1991), Cabri II (Laborde, Baulac, \& Bellemain, 1988), Geogebra (Hohenwarter, 2001), Cinderella (Richter-Gebert \& Kortenkamp, 1999), Cabri 3D (Laborde, 2004)], on the other hand, provide multiple dynamic paths for learning, and an understanding of mathematics does not come from memorizing terminology, processes and proofs. Dynamic Geometry allows for the creation of interdependencies and intra-dependencies between mathematical objects, diagrams and tools (Patsiomitou, 2021, p. 80).

The perception of a visual image of a geometric object does not coincide with the mental object a student has in mind. For example, the orientation of the geometrical object could play an important role in students' understanding of the geometrical figure. High-school students' ability to rightly and accurately construct a figure using static or dynamic means relates to two factors: whether they know how to construct it, and whether they know why the concrete method of construction results in a figure with concrete properties and not a drawing. The answer to the question "How do we construct it?" relates to what is called procedural knowledge. The answer to the question "Why to construct it in this way?" relates to what is called conceptual knowledge. There is a duality or polarization in mathematical knowledge between "knowing how" and "knowing why" (Scheffler, 1965; Hiebert \& Lefevre, 1986).

Instrumental trajectories are not just construction instructions, which are to say, a set of information which provides the properties of the figure as the figure is constructed. Instrumental trajectories can show us the dependencies that exist or can be created between different tools. For example, translating a point using the translation tool is connected--in terms of having the same constructional effect--to the construction of circles of equal radius on a straight line-segment. An instrumental path/trajectory is considered complete when it connects the verbal description to the visual description. The question is obvious: can students construct different instrumental paths and, if not, what processes can contribute to such a path?

From my experience in class, I know that many students find it difficult to reconstruct the figures they see in their textbook. This is because they do not understand the connections between geometric objects. On the other hand, the teachers take it for granted that their students know how to construct the figure in a given problem and proceed to solve it, without focusing on the figure's construction. As a result, students lack a profound understanding of the concepts involved, since understanding the connections and dependencies between the objects in a figure is the most important step towards solving a problem. Here is a recent example from my Geometry teaching to students in the 3rd year of high school. The Mathematics textbook (Argyrakis et 
al., 2007) contains a problem: "On the side $A B$ of triangle $A B C$ we take point $D$, so that $A D=2 / 3 A B[\ldots]$ " (p. 226). When I asked the students how to construct the figure, I realized that some of them found it hard to come up with the theorem relating to the division of a segment into equal parts. The answers I received related to measuring the segment and then dividing it, always with a ruler. Students found it hard to disconnect the process from the specific construction case. In other words, they were unable to recall the relevant theory, connect it to the notions, and apply it. In addition, they could not visualize the construction with a different orientation--an issue which relates to van Hiele's theory (e.g., Patsiomitou, 2008a, b, c, d; 2012a, b).

The students use their conceptual knowledge to construct a figure in different ways. For example, they can use a definition or a theorem as the basis for the construction of an equilateral triangle: thus, according to the definition, an equilateral triangle is a triangle all of whose sides are congruent. This means that students can use their rulers to construct a triangle with three equal sides. Alternatively, if the student knows the theorem "an equilateral triangle has three angles equal to 60 degrees", they can also use the information incorporated in it and use a protractor to construct a triangle whose angles are equal to 60 degrees. In the DGS software, students have to cooperate with the environment in order to accomplish their constructions. They cannot "touch" the tools, but they can create constructions using the mouse in accordance with their mental representation. However, if a student has not grasped the concept of "equilateral triangle" but knows how to construct an equilateral triangle, then $\mathrm{s}$ /he can perceive the properties of the figure and can be guided, through proper questioning, to discover them.

There is usually more than one instrumental path with which we can construct a geometric figure. Consider, for example, how we can construct the bisector of an angle: a) with a protractor, which is based on knowledge of the definition, as we have to measure the angle and then construct the bisector using the protractor, b) using only a ruler and a compass without measuring the angle, which is based on knowledge of the definition and the related theorem. Are there ways to connect the different processes with the proper configuration of instrumental paths? This explanation can only be achieved by means of a pseudo-Toulmin model, which analyzes the connections and relationships between tools and concepts.

The constructions proposed in the textbooks have a theoretical basis: i.e., each step is linked to a definition or theorem. The construction of a midpoint, for example, is based on the definition, while the construction of an equilateral triangle is based on the 1st Proposition of Euclid's "Elements" (Book I): "To construct an equilateral triangle on a given finite straight-line" (Fitzpatrick, 2007, p. 8).

In general, the school textbooks provide a figure on the basis of which the students are called upon to solve the problem by applying the definitions and theorems in the section. The school textbook should explain and provide guidance in how to use the tools to construct a figure, as well as the steps (i.e., what are the primitive objects used for the construction, at which point we use the proper tool) we can follow to successfully construct it. As I mentioned many times in previous works (e.g., Patsiomitou, 2008a, b, c), an alternative way for the teaching of geometry in schools is by using transformational geometry. Reasoning with transformations should be a central theme of the learning of geometry. How could we explain the whole process using the different tools of a DGS software? We can use a pseudo-Toulmin model in which a student could understand the use of the different tools and their supportive role for the development of the process.

In the current study I shall analyze, using instrumental decoding and pseudo-Toulmin modelling (Patsiomitou, 2011, 2012b), several conceptual and instrumental learning trajectories for the teaching of, or the conducting of action research into Geometry, which employ digital dynamic means: in other words, the construction of instrumental learning trajectories within "Dynamic Euclidean Geometry" (Patsiomitou, 2021).

\subsection{Instrumental decoding and the pseudo-Toulmin's model}

Competence in the DGS environment depends on the competence of the cognitive analysis which students bring to bear when decoding the utilization of software tools, based on Duval's $(1995 \mathrm{a}, \mathrm{b})$ semiotic analysis of students' apprehension of a geometric figure. Duval (1995b, pp.145-147) has distinguished three kinds of operations. During the development of a construction, I also think that the student has to develop three kinds of apprehension when selecting software objects which accord with the types of cognitive apprehension outlined by Duval (ibid.) namely perceptual, sequential, discursive, and operative apprehension. In concrete terms, the competence of instrumental decoding (Patsiomitou, 2011, p.362) in the software's constructions depends on the sequential apprehension of the tool's selection, the verbal apprehension of the tool's selection and a place way type of elements operation on the figure due to his/her perceptual apprehension. In concrete terms, the competence of instrumental decoding in the software's constructions depends on: a) the sequential apprehension of the tool's selection (i.e., s/he has to follow a predetermined order); b) the verbal apprehension of the tool's selection (i.e., the student has to verbalize this process), and c) a place way type of elements operation on the figure. Then s/he has constructed the operative apprehension (Duval, 1999) of the DGS figure's elements for the construction. 


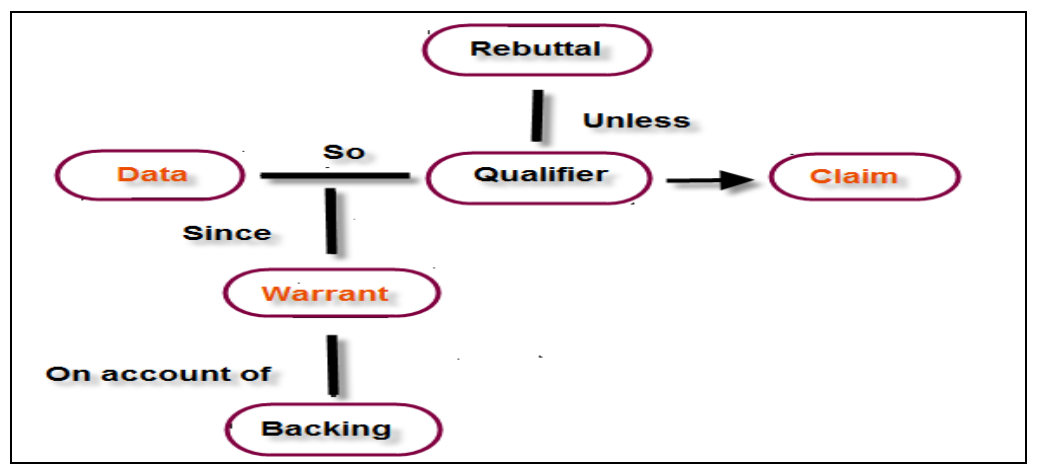

Figure 1. Toulmin's (1958) model of argumentation (adapted, Patsiomitou, 2012b, p.57)

Toulmin's (1958) model of argumentation is a model which relates the involved elements: claims, data, warrants, backings, qualifiers and rebuttals in the argument formulated by an individual (or a group of students that participate). These elements are represented in a diagram below in which the relationships between them are expressed in sequential order. In other words, Toulmin's model consists of the elements described above, which are explicit or implicit. Several times an argument does not include qualifiers and rebuttals. Krummheuer (1995) suggested and applied a reduced model of the original scheme, consisting of claims, data, and warrants of arguments "to examine the learning of mathematics in the context of collective argumentation" (p.11). As suggested by Krummheuer (ibid.), during a classroom activity (or for the current study during group cooperation) one or more students could be contributing towards the formulation of the argument, attempting to convince the other participants of the group, including the class teacher (or the researcher). In a pseudo-Toulmin's model $(\alpha)$ the data could be an element or an object of the dynamic diagram, and $(\beta)$ a warrant could be a tool or a command that guarantees the result which is the claim (or the resulted formulation). For example, a drawing of a parallelogram is the data (D), the theoretical dragging is the warrant (W), and the figure of the parallelogram is the claim $(\mathrm{C})$. This means that a student can theoretically drag a point-vertex of a drawing-parallelogram and transform it into a figure-parallelogram, trying to acquire additional properties. Also, I have extended the pseudo-Toulmin's model in order to express a relationship between the figures, something that I am going to present in the current study.

In the sections that follow, I shall present a research synthesis (e.g., Patsiomitou, 2006, 2008, 2012): three examples of instrumental learning trajectories, in which the interdependencies among the tools and meanings are analyzed. My aim is to combine and synthesize different primary qualitative research studies and make their results more generalizable.

\section{An instrumental learning trajectory combining technology and aesthetics}

Research methodology. This part of the current study investigates the development of formal proof in the dynamic geometry environment of Geometer's Sketchpad v4, using custom tools (Patsiomitou, 2008c) which combine technology and aesthetics. The Ancient Greeks, particularly the Pythagoreans, believed in an affinity between mathematics and beauty, as described by Aristotle "the mathematical sciences particularly exhibit order, symmetry, and limitation; and these are the greatest forms of the beautiful" (Sinclair, 2004). According to Sinclair (2004, p.262)

"many mathematicians (e.g., Hadamard, 1945; Penrose, 1974; Poincaré, 1913) as well as mathematics educators (e.g., Brown, 1973; Higginson, 2000) have drawn attention to some more process-oriented, personal, psychological, cognitive and even sociocultural roles that the aesthetic plays in the development of mathematical knowledge". Sinclair (ibid.) declares that "they associate the aesthetic with mathematical interest, pleasure, and insight, and thus with important affective structures...".

For the construction of custom tools mentioned above, the role of aesthetics is also important. Perhaps is developed an expectation that the results of the study will demonstrate how the work with DGE and its aesthetics will motivate students to build meanings of mathematical concepts. This part of the study does not focus on motivation stemming from the improved aesthetics obtained through dynamic geometry constructions. In this study is demonstrated how the instrumental paths that are produced in the DGE environment are not simply beautiful but they have other aesthetic qualities. In other words, they can, as digital material entities, be more than beautiful "drawings'; they can be 'figures' with geometric properties referring to the theoretical object (Laborde, 2005). And these properties are perceived by the students as they interplay with it.

Firstly, it is important to draw out the connections between "chunking" and custom tools. The resemblance is evident, but the process of using a custom tool seems to be different from the act of creating one, which may or may not have chunking as its goal. It does not mean that any act of creating a custom tool coincides with the act of chunking, but it cannot just be a faster way of doing or repeating things, helping our memory with a 
difficult construction. To create a new tool, we begin by building the construction we want to define as a tool. This construction will also serve as the 'definition' during the tool creation process. For instance, thanks to the manner in which it is constructed and saved as a custom tool, an equilateral triangle can be defined, and thus categorized, as a geometric object with given properties. If, for example, the figure is constructed using the rotation command, then every side is the product of the adjacent side rotated by 60 degrees about the vertexcenter common to the two sides. The students can thus categorize the equilateral triangle in their mind with the following properties: "a triangle with sides of equal length and angles equal to 60 degrees". In this sense, through the custom tool, the equilateral triangle --object-- acquires a conceptual categorization as well as the meaning of the archetypal / primitive object. Davis \& Tall $(2002$, p.151) declare that "The fact that we can talk about chairs, or a chair, without referring to or pointing at a particular world-thing is a result of a process of perceptual categorization. The concept 'chair' is a mental concept, and not a corporeal world-thing." Paraphrasing last expression "the concept 'custom tool-equilateral' becomes a mental concept and not a corporeal artefact" in the screen.

For example: Figures 2 and 3 illustrate two different instrumental paths of constructing the original /initial right triangles, and include transformations which will subsequently be used to construct the custom tools. In Figure $2 \mathrm{a}$, the right triangle with vertical sides in a ratio of $2: 1$, has resulted from joining the vertices with the middle points of the opposite sides of the square. In Figure 3c, a triangle with vertical sides in a ratio of 2:1 has been constructed directly.

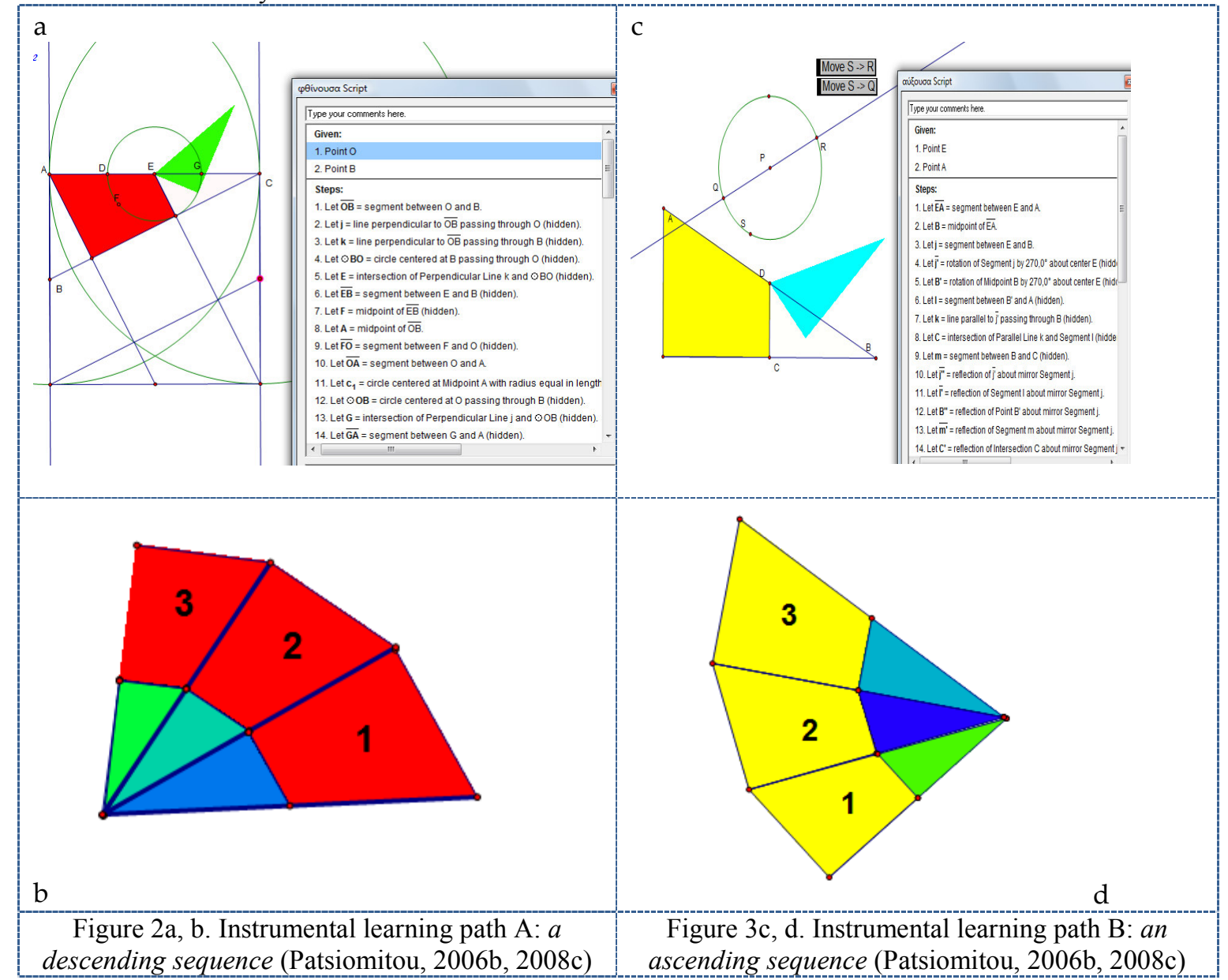

In both constructions all the lines that are not essential have been hidden to the operation of the custom tool and subsequently applied the transformation in the manner illustrated. The rearrangement demonstration occurs on the right triangle whose vertical sides are proportional to the original right triangles' sides in a ratio of 2:1. The application of the transformation to the vertex "acts as a hinge allowing the learner to rotate one of the connected triangles by direct manipulation. This process can be repeated resulting in the formation of a combination of shapes, while the area of all these shapes remains the same" (Sedig, \& Sumner, 2006). Rearranging the construction, students could be helped as new information is highlighted otherwise difficult to understand (Spence, 2001, reported in Sedig, \& Sumner, 2006). Prior to creating the custom tools, I also measured the lengths of the sides and calculated the areas of the initial construction. Although the final result of 
the two instrumental paths for constructing the initial right triangle including the rearrangement appear identical, they lead to ways of constructing a custom tool whose application provides different results in both computational and constructional terms. For example, applying the tools three times in succession produces the results in figures $2 \mathrm{~b}, 3 \mathrm{~d}$. This means that as we can see in the illustration, the areas of the shapes steadily decrease (figure $2 \mathrm{~b}$ ) or increase (figure $3 \mathrm{~d}$ ). Concretely, applying the custom tool using the appropriate method for constructing it, we take different constructional, representational results:

- Instrumental learning path A: the longer vertical side of the initial triangle becomes the hypotenuse of the next right triangle in the sequence. Meaning the sequence of the measurements and calculations that emerges is descending.

- Instrumental learning path B: the hypotenuse of the initial triangle becomes the longer vertical side of the next right triangle in the sequence. Meaning the sequence of measurements and calculations that emerges is ascending.

If we iterate the initial points of the construction of the tool, we can take different results relating to the construction the measurements and the calculations. As it is well known for someone who uses the Sketchpad software the result of the process of iteration (Steketee, 2002; Jackiw, \& Sinclair, 2004) is the construction of the tables that repeat the process of initial measurements and calculations in dynamic linking with the diagram, thus increasing (or decreasing) the level of the process of iteration while the software adds (or removes) the next level of measurements (or even calculations), whereas in the first column of the table, the sequence of the natural numbers is presented (Patsiomitou, 2007).

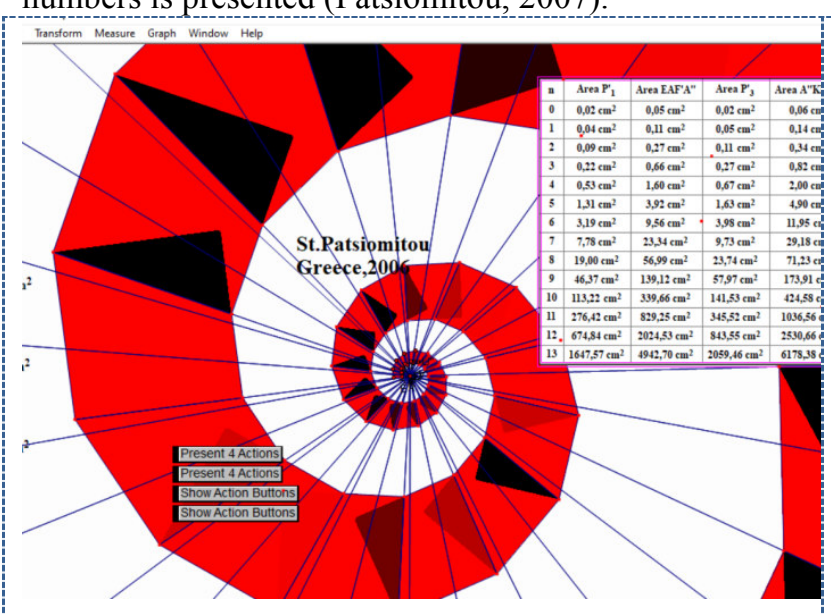

Figure 4: The construction of the tables (Patsiomitou, 2006b, 2008c)

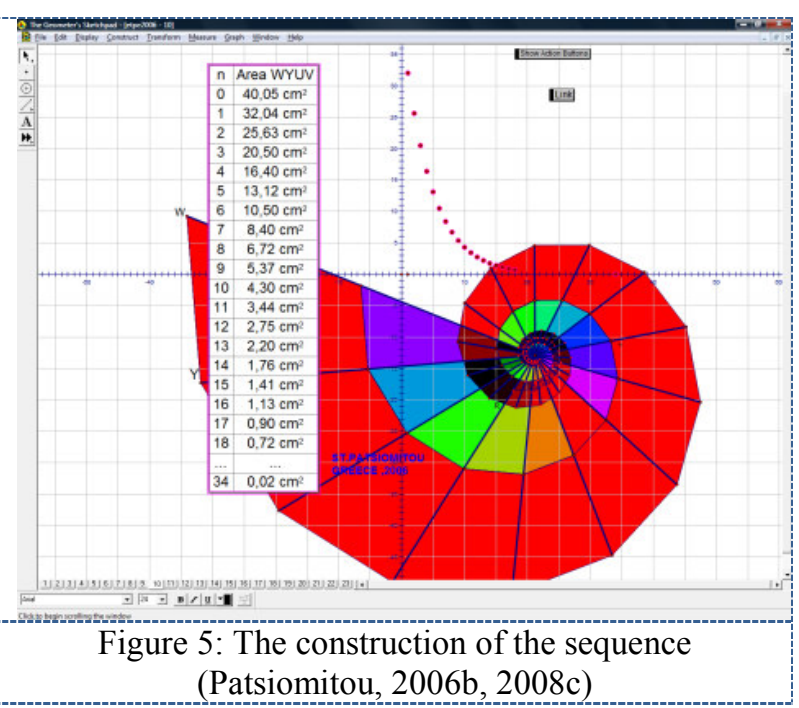

The process of animation can produce the changes in the tabulated measurements (/calculations) that allow the user to examine the dynamic process. Figures 4, 5 illustrate the construction of the tables that repeat the process of initial measurements and calculations of the ascending sequence in dynamic connection with the shape. In the software, via the process of iteration we have the potential of the constructions thus becoming more complex being in theory rendered inductively to infinity. This function of the software also constitutes a certain crucial and essential particularity, while the construction with a compass and a straightedge as static tools of geometry has a beginning and an end (e.g., Patsiomitou, 2007, 2008c, 2019c).

\subsection{The experimental study}

The qualitative study (Patsiomitou, 2008c) was conducted in a class at a public high school in Athens, Greece and involved twenty-eight volunteers, students aged 15-16, randomly divided between the 'experimental' and the 'control' teams, with 14 students in each. I ensured that both teams consisted of equal number of boys and girls, equal distributed to their achievement in mathematics. The students were friends, which fostered group discussion. The methodology of the class experiment is discussed in the ATCM paper (Patsiomitou, 2008c) and includes the investigation of the following open problems:

Problem A. Construct sequential right triangles with vertical sides in a ratio of 2:1, so that the longest vertical side takes the place of the hypotenuse in every new repetition. Calculate the hypotenuse in every new repetition. (Instrumental path A)

Problem B. Construct sequential right triangles with vertical sides in a ratio of 2:1, so that the hypotenuse takes the place of the longest vertical side in every new repetition. Calculate the hypotenuse in every new repetition. (Instrumental path B)

Students of the experimental team had only worked on the Sketchpad v4 using the pre-constructed custom 
tools I had created (mentioned as instrumental, and later applying the iteration process. I did not consider it necessary "to separate the 'teaching of mathematics' from the 'teaching of the tool', preferring to integrate the appropriation of the functioning of a tool with the learning of the mathematics" (Olivero, \& Robutti, 2007). The experimental team discussion was designed to record how students would react while interacting with the tools. My aim was in this way to adapt the experiment to real classroom conditions. It provides an example of the interplay between the students and the researcher-teacher and reflects Kaput's (1992) writing on the importance of technology in mathematics education, concerning the feasibility of innovative practices emanating from technological advents, which were otherwise impracticable. I had hooked a projector to my computer, and the students could participate individually or as a group during the session by interacting with the activity. The experimental sessions were videotaped. The analysis of the results that follows is based on observations in class and of the video. Qualitative research was employed to investigate the impact of the reported above curricular changes on students' geometrical thinking. The methodology consisted of action research (Bogdan \& Biklen, 1998) and "theory-building" (Eisenhardt, 2002) from case studies. I analyzed the data using the constant comparative method of grounded theory (Glaser \& Strauss, 1967). The group was initially tested to produce a figure with the properties described in the problems, mentioned above. For instance, in Instrumental path A, the students used the custom tool A and produced a descending sequence of measurements and calculations (relating to lengths of sides or to areas), while the use and application of the custom tool B, in Instrumental path B, results in an ascending sequence. In both cases, the ratio of the areas is stable and equal to 1.25 (Figure 6). The students began by experimenting with the 'rearrange the figure' action button. They realized, though did not see the hidden circle on which the point of triangle's vertex is moved, that "there is a circle through which the vertex of the triangle moves while turning through 180 degrees". The use of the custom tool aroused the students' interest as they played with it. The students had not learned or even heard about the concept of the sequence or the limit. Initially, the students verified the relationships between the areas of the sequential triangles or trapeziums, by applying the tool several times over. Then, knowing what would ensue, I suggested applying the tool to the sequential vertical sides of the figure (Figure 4,5 ).

\subsection{A discussion with the students of the experimental team}

The students try to apply the custom tool to a small triangle on screen. And note, surprised like the others, that the construction is repeated even if the triangle is very small. The students noted that the values of the areas of the emerging descending (or ascending) sequence depended on the construction of the initial custom tool. When they applied the iteration process, the results were stupendous: the students could press the presentation buttons, rearranging the triangles and they stated:

345. Students: The figure becomes a spiral. It resembles the nautilus scheme ... anyone can believe that the figure does not finish. (Figure 5)

The tables that resulted from the application of the iteration process led them to note that the ratios of the areas remained stable as the sides changed in line with a pattern.

347. Students: All the numbers (in the same column in the table) are related in the same way, which is why they have the same proportions in the table.

348. $\mathrm{M}_{2}$ : But we cannot be sure what is happening in its depths and she pointed into the spiral that had formed. (Student $\mathrm{M}_{2}$ speaks pointing to the spiral).

349. Researcher: What do the areas do when the values of the sequence increase?

350. $\mathrm{M}_{4}$ : They get smaller... they go down to zero.

351. $\mathrm{M}_{1}$ : Then we wouldn't have any geometric figures at all.

352. $\mathrm{M}_{2}$ : The values tend towards zero.

I asked them to use the dilate tool to increase the size of the figure.

355. Students: Our initial triangle (be mentally) becomes as large as the room; it can become infinite.

356. Students: Once again, the ratio remains constant.

The students experimented with the table of measurements, plotting the points in a graph. Fig. 5 illustrate the plotting points of the descending and the ascending sequence.

382. Students: The areas become so small they tend to 0

383. Researcher: What is the domain of the sequence?

384. $\mathrm{M}_{2}$ : Isn't $N$ the Natural numbers?

385. $\mathrm{M}_{1}$ : As $N$ (natural numbers) increases, $E$ (the area) grows ever smaller and as $\mathrm{N}$ increases, $\mathrm{E}$ grows ever larger.

386. $\mathrm{M}_{8}$ : Yes, but there might be a second domain (pointing to the values of $N$ ) from which point forward the sequence tends to zero.

The students consequently had an environment of linking visual active representations (e.g., Patsiomitou, 2008a, b, 2010, 2012a, b, 2019 a, b, c) in which the figure of the fractal had been linked with the table of the measurements via the functional process of iteration, which continuously could be linked with the graphic 
representation of the sequence.

388. Researcher: What do you think will happen to the area if we increase the number of iterations?

389. $\mathrm{M}_{6}$ : because we are dealing with the area of triangles rather than the area of a point, it is impossible for the area to reach zero; we can't depict something of zero value.

The students see a point on the screen, but their intuition tells them the point is a triangle with an area other than zero. This means they have intuitively formed the concept of the infinitesimal quantity of the area of the triangle. This is another point at which we can discern the degree to which the student's awareness has been heightened through their experimentation using the software. The connection of the concept image with the concept definition of the meaning (Vinner, 1983) was developed through the environment of the software. The custom tool process derived from instrumental path $B$ helped the students understand that the values of the sequence increase steadily. The graphic representation of the sequence of areas displayed / showed the isolated points as they appear on screen.

417. Researcher: How can we work out the length of this side? I pointed the hypotenuse out to them.

418. $\mathrm{M}_{3}$ : If we assume that the vertical side one is $a$, then the next vertical side is $2 a$, since it is double its length. By applying Pythagoras' theorem, we can work out the length of the next side.

Their initial observations were confirmed using the proofs of the formulae which could be hidden/shown in the software, which motivated the student to move on to the next step while gradually leading them empirically and by means of formalistic processes to the construction of the meaning of the sequence and of geometrical progress. They reached conclusions relating to the way in which the tool is used, and hence about meaning including limit, a sequence of values and geometric progression. Having worked out the formulae and hidden them using the hide/show buttons, I made sure the students clicked to reveal the proof that confirms their efforts. When they had noted that the relationship between the sides and areas of the sequential figures was constant, I asked them:

426. Researcher: How did this result (1.25) come about?

427. Students: It is the same ratio we saw earlier in the tables. The calculations of the areas produce the same result. The results confirm the correctness of the tables.

428. $\mathrm{M}_{8}$ : Every number is the previous number multiplied by 1.25.

429. Researcher: How does the number 1.25 result?

430. M7: It's a constant value which results from every division of the two continuous areas of the triangles (or the trapeziums) .... each triangle area, results from the previous area when divided by 1.25.

To understand why a maths activity for students built with DGS is powerful needs from us an objective analysis. Students through the instrumental genesis process (Rabardel, 1995; Trouche, 2004) are able to build up instrumented action schemes that combine technical and conceptual aspects. The mental activities render meaningful the enacting on the above technical actions. As Drijvers (2003) writes "The instrumentation schemes integrate technical skills and conceptual insights".

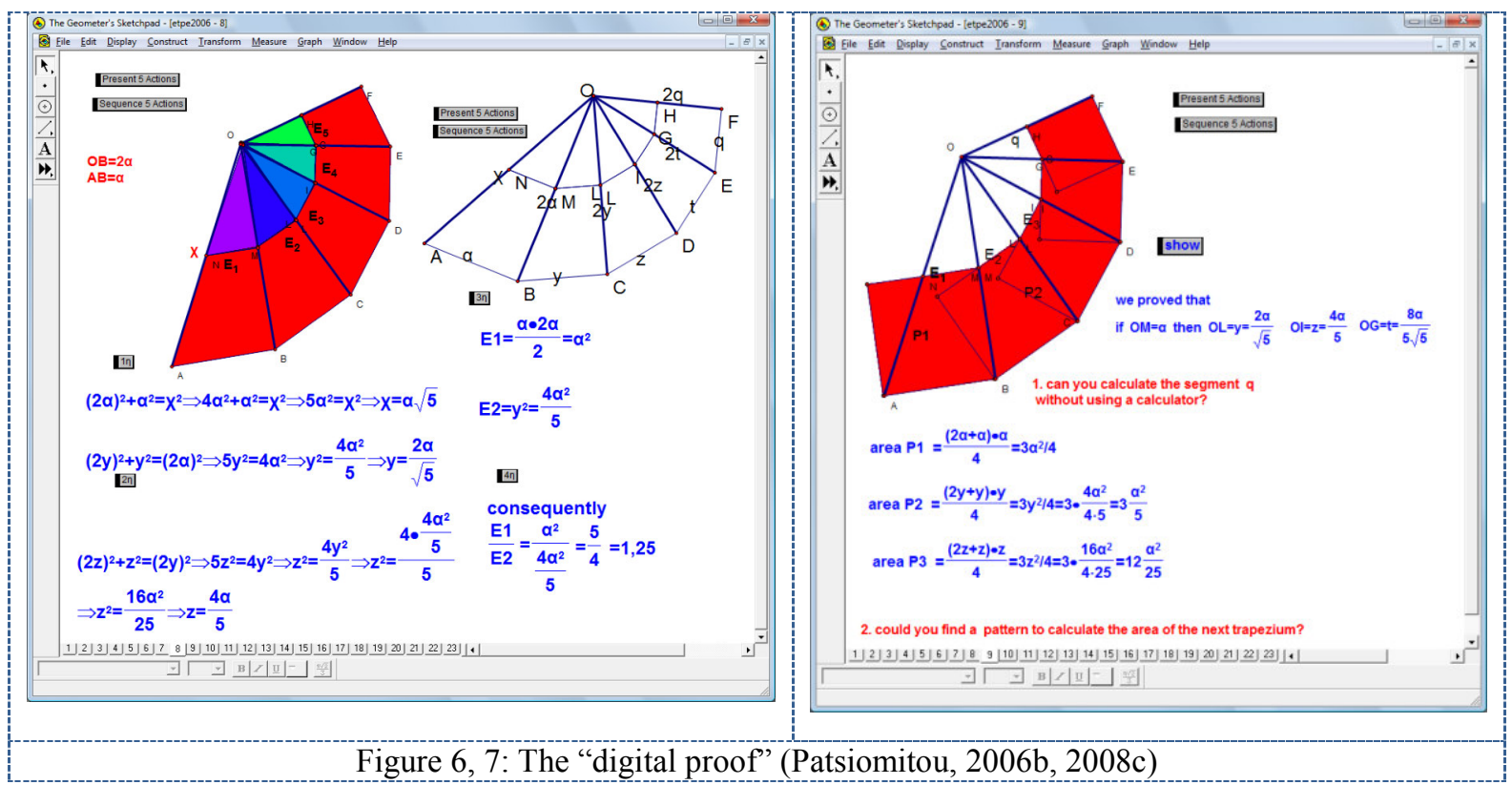

The analysis of student discussions includes the following objectives: the construction of meanings, recognition of instrumented action schemes through the emergence of theorems and concepts-in-action. I noted the following: 
[341-345]: use of tools (custom tool and iteration command) for the construction of an attractive image. [347-383]: construction of the meanings of the sequence, of the geometric progression and the intuitive construction of the limit of the areas which tend to zero.

[383-386]: students interacted with multiple representations in order to bridge processes and objects

[388-389]: the intuitive construction of the meaning of infinitesimal quantity.

[417-418]: the emergence of a theorem-in-action and the "digital proof" construction

[426-430]: the custom tool and the iteration process as forms of chunking and the emergence of theorems and concepts-in-action (Vergnaud, 1998).

During the session, the students formed a usage scheme for using the custom tool and the iteration process. The custom tool led students using it to discover the properties of the more complex figure which therefore required the subject to act on the tool (instrumentation of the tool) while the artefact simultaneously interacted upon them (instrumentalization of the tool). The different way in which the tool was constructed encouraged the students to build the meaning for the concept of the ascending and descending sequence. They correlated the construction of the nautilus spiral with the diagram on the screen and they were led by the tables to construct the meanings of the limit and the infinitesimal.

As we "cannot look inside the heads of the students to observe the mental schemes" [...] "we focused on the techniques, which can be considered as the observable parts of the instrumentation schemes" (Drijvers (2003). For example, the process of rotating a triangle by specifying a mark angle of $180^{\circ}$ and marking point $\mathrm{F}$ as the centre results in a congruent triangle as the original triangle but rotated through $180^{\circ}$. Any effort to modify the lengths of the sides of the original triangle by dragging its vertex will result in an equivalent modification of the dependant rotated triangle due to transformation. The rotation of the triangle in the software diagrams results to an instrumented action scheme which leads the students to conceptually grasp the meaning of congruent triangles, having a significant impact: the student structure a utilization scheme of the tool, and consequently a mental image of the functional/operational process of rotation, since any modification/ transformation of the initial triangle (input) results in the modification/transformation of the final triangle (output) (Patsiomitou, 2008a, b, c).

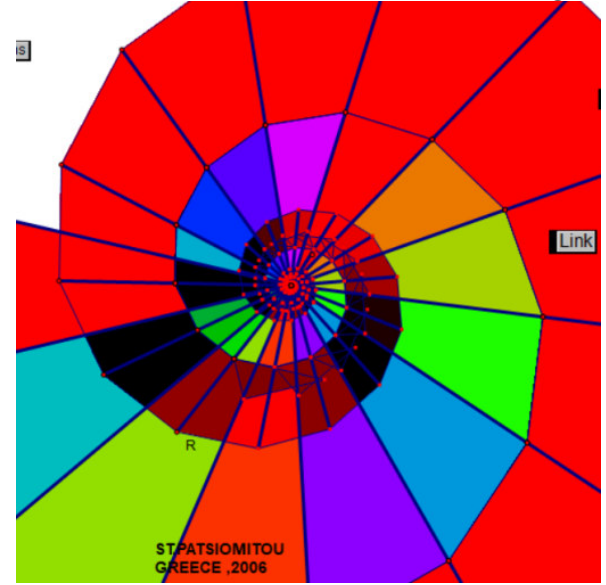

Figure 8. Implementation of the custom tool (Patsiomitou, 2006b, 2008c, 2019c)

In such mental schemes technical and conceptual aspects are interwoven (Drijvers, 2003). The instrumentation process proceeding through the tools affects and diagrams the way the user thinks, while the student also exerts an affect on the tools and acts by formulating his thoughts through the instrumentalization process. The students structure a usage schema in order to use the custom tool while simultaneously organizing their activity through the tool's own utilization schema. On the other hand, through the application of the custom tool the possibility is given to the user to acquire an inductive way of thinking for the finite steps of the construction but the generalisation with regard to the constructional result can be achieved from the process of iteration which inductively renders the construction theoretically to infinity (Brown, 1973). For example, students formulate the sentence "Every number is the previous number multiplied by 1.25 ". This sentence includes a generalization. Students' utterances such as "all the numbers are related in the same way", "the values tend towards zero", "The areas become so small they tend to 0", contain concepts-in-action and theorems-in-action (Verganud, 1998). Vergnaud (1998) insists that "theorems-in-action cannot exist without concepts-in-action, as theorems cannot exist without concepts-in-action, and vice-versa". What is important to note is that the student $\mathrm{M}_{1}$ thus guided to formulate the theorem-in- action "as N (natural numbers) increases, E (the area) grows ever smaller..." was not generally successful at Maths. The formulation of the student's thoughts includes a hidden/implicit "if... then" expression. $\mathrm{M}_{1}$ does not express his thoughts exactly; his phrase is incomplete, but he seems to understand the process. He means: "if N (natural numbers) increases, then E (the area) grows ever smaller...". According to 
Vergnaud (1998) "when operational invariants are expressed and involved in systems of concepts and symbols, their cognitive status changes, up to the point that schemes can sometimes become algorithms. When the relevant properties of the mathematical objects and operations involved in action are made explicit, it becomes possible to analyse their connections, and eventually to demonstrate that a certain set of rules, for a certain class of situations, is effective" (p.176).

The environment also helped them discover that "it is impossible for the area to reach zero" and "might be a second domain (pointing to the values of $N$ ) from which point forward the sequence tends to zero". This marks the start of a transition to a level of rigour which emerged with the building of the concepts in the dynamic geometry environment. Descriptively, the students are urged to develop a theoretical way of thinking and despite the fact that the observations were limited to numerical relations the students answered to qualitative questions concerning the dynamic behaviours of mathematical objects, since the process as it is being built progressively guides them to examine more parameters. With respect to the affordances offered by the dynamic geometry environment, was developed the proving process. This uses the proof process to verify the on-screen 'visual theorem' which was argued visually. The students constructed their arguments by forming the visual representations as well as the symbolic representations derived from the formulae. They concluded the properties from the geometric shape and ended up with formulations of algebraic rules.

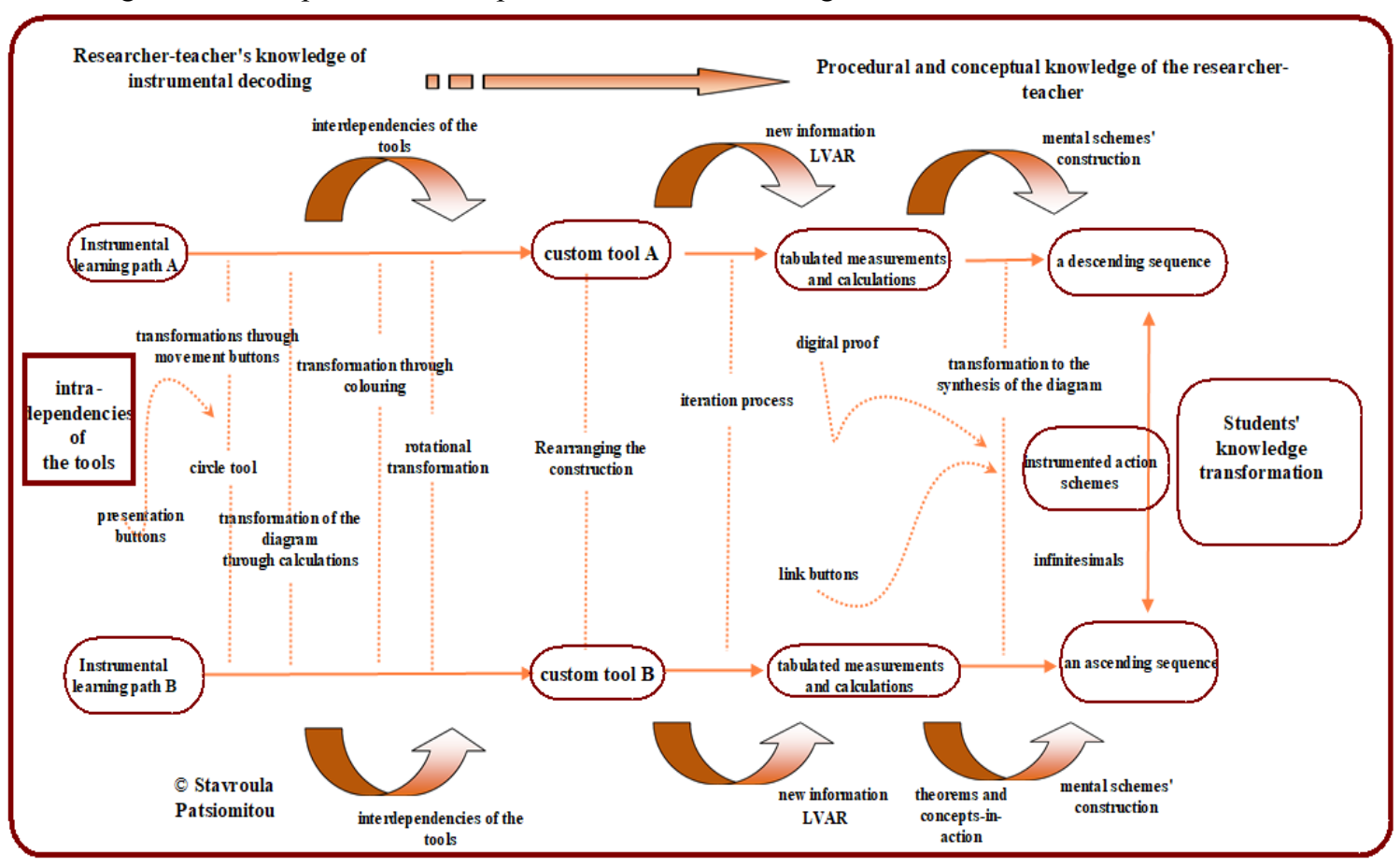

Figure 9. Students' knowledge transformation through the use of instrumental learning trajectories

In a DGS environment, the hide/show action buttons act as a tool which supports focusing on the proving process. In direct connection with the figure, hiding and showing the formulae for parts of the proof leads to a different form of proof: a combination of traditional and digital means which could be called a 'digital proof' (Patsiomitou, 2006b, 2020b, in Greek). The custom tool with which the interaction takes place during the mathematical activity is directly linked to the construction of the artefact-spiral. The students accommodate the tool to their needs. This means that a student organizes his/her actions by mental schemes and uses the custom tool to discover the properties of the more complex shape (which is an extension of the structure), as the tool acts on the student in order to extend his/her mental scheme. As a consequence, the use of the custom tool which includes the mental scheme of its use organizes the activity of the subject and leads to a more complex structure by creating a new mental scheme for the new object with its properties. In our case, a new mental scheme is for example the ascending/descending sequence or the meaning of limit for the triangles' areas. Meaning that, apart from guiding the student to more complex constructs, the appropriately constructed custom tool also renders the mental and dialogic processes more fruitful, and thus leads to higher levels of abstraction. The constructed spiral allows the students to grasp the sense of infinity, and is imbued with numerous mathematical properties.

According to Fangchun Zhu (2020) "DGS not only affects the learning process of the students but also affects the teaching methods at the same time" (p. 21). In my opinion, a dynamic geometry environment not only impacts on the learning process, it also affects the construction of instrumental learning paths and, consequently, the students' knowledge. In other words, a student's knowledge and instrumental decoding competence affects 
their learning of mathematics. Moreover, the researcher-teacher's instrumental decoding competence leads to transformations in elements of the instructional path, adding dynamic transformations that can help students transform their knowledge efficiently.

\section{An instrumental learning trajectory for the meaning of rectangle}

Research methodology: The following process is a part of a research study which I was conducted in a public high school class in Athens (Greece) (January -April, 2007). It sought to investigate ways in which the Geometer's Sketchpad dynamic geometry software mediated the development of students' van Hiele levels (e.g., Patsiomitou, 2008a, b, 2012a, b) by focusing on the impact the software's transformations and interaction techniques (Sedig \& Sumner, 2006) have on the way in which students construct meanings and proof. The students first had been evaluated by their responses to the 20 questions of the 25 multiple-choice questions van Hiele test of Usiskin (1982). In grading the students' tests, "a student was assigned [the] weighted high score" described by Usiskin (1982, pp.22-23). This means s/he had been determined to be in level 1 if s/he answered 3 or 4 of 5 first questions of the Usiskin test correctly (with 4 being the stricter criterion called for by Usiskin). The participants had no knowledge of the DGS software or any related software. The study developed into a didactic experiment of action research (Kemmis \& McTaggart, 1982; Schön, 1983). The students of the experimental group followed a DHLP (i.e., a re-conceptualized learning path of four strands for the teaching and learning of parallelograms in geometry, using The Geometer's Sketchpad software), which I conceived through a thought experiment, reported in details in my study "A Linking Visual Active Representation DHLP for student's cognitive development" (Patsiomitou, 2012b). In the current study, I shall present an excerpt of the research process, but viewing it in terms of the construction of instrumental learning paths [see also, the study "Students movement through van Hiele levels in a guided reinvention process" (Patsiomitou \& Emvalotis, 2010]. I shall report them enriched with the cognitive analysis of students' utterances in detail with the meanings I developed later (e.g., theoretical dragging, instrumental decoding, instrumental learning paths). The group consists of students M7, M8, and M13. Their van Hiele level was 2, 2, and 1-transition-2 respectively. The students' task was to construct a rectangle using the "Construction" menu. This construction came after the construction of a parallelogram which had given the students experience of basic software tools like the point tool, the straightline tool, and the parallelism and perpendicularity commands in the Construction menu.

\subsection{Building and transforming a rectangle}

The aim of the research process was for the students to obtain the competence to build and transform linking structurally unmodified representations of parallelograms. The groups started with the most general concept of a parallelogram in which the opposite sides are parallel lines, before specifying by imposing the properties that produce a rectangle, a rhombus, and a square. The students had to build parallelograms with an emphasis on the "construction" menu. My intention was to introduce the Sketchpad tools and commands 'step by step', "in parallel with the corresponding theory" (Mariotti, 2000, p.41), because from my previous experience the students too often make mechanical use of the software and, this in return renders them unable to understand the logic behind the command options. Furthermore, they would not be able to construct the connections between the spatiographical field and the theoretical field of the software. I have recorded in detail how the students came to understand the use of the tools and correlated this ability with the partial construction of the meanings. The aim of the construction problems of the research process was for the students to do the following (Patsiomitou, $2012 \mathrm{a}, \mathrm{b}$ ):

- $\quad$ Construct a drawing and investigate it using experimental dragging. My aim was for the students to face cognitive conflicts.

- Become able to dynamically reinvent the properties of the figures through theoretical dragging (Patsiomitou, 2011). Moreover, to connect the properties regarding their sides and angles (primary elements of the figure) and the properties of the figure regarding their symmetry lines (secondary elements of the figure).

- $\quad$ Provide a figure by instrumentally decoding their mental images with the software tools. The students have to first transform the verbal or written formulation ("construct a parallelogram," for example) into a mental image, which is to say an internal representation recalling a prototype image (e.g., Hershkovitz, 1990) that they have shaped from a textbook or other authority before transforming it into an external representation, namely an on-screen construction.

- $\quad$ Provide an oral description of the process, meaning the path they followed in constructing the figure. This process includes the relation of procedural knowledge (use of the tools, use of the theorems or definitions) with the students' conceptual understanding, meaning the use and building of the relative meanings through the process.

- $\quad$ Become able to perceptually form a hierarchy of the figures through linking representations.

The connection with the conceptual knowledge will occur as a result of the justification of the process 
"providing good arguments which can make the solution acceptable" (Mariotti, 2000, p. 34) at the theoretical field of the software within the system of Euclidean Geometry. As a consequence, "solving construction problems in the [DGS] environment means accepting not only all the graphic facilities of the software, but also accepting a logic system in which its observable phenomena will make sense" (Mariotti, 2000, p.28).

Instumental path A: Drag the vertex of the parallelogram you have constructed until it becomes a rectangle. Then, find a path to construct a figure of a rectangle.

The students could use only the commands "construct a parallel/ or perpendicular line" from the Construct menu which they already knew from the previous investigated activity. I limited the students to using the fewest commands possible, preferring they use only the necessary tools and the theories of geometry. The rectangle is a fundamental meaning in parallelograms. Students are able to recognize the prototype image of the rectangle from the first classes of primary school. The obstacles regarding the prototype image of the rectangle have broadly been discussed (Hasegawa, 1997; De Villiers, 1994; Laborde, 1994; Fischbein, 1993; Parzysz, 1991; Sfard, 1991; Hershkovitz, 1990, in Monaghan, 2000, p. 187). Most students "recognize a rectangle where the vertical width is greater than the horizontal length [...]. their concept of a rectangle has become fixed as being synonymous with an oblong" (Monaghan, 2000, pp. 186-187).

Through the experimental, and then theoretical dragging of a vertex of parallelogram is pursued the students to focus on the figure's structure that "can be specialized [from a parallelogram] by imposing more properties" (De Villiers, 1994, p. 14) and can be generalized from the concept of square. The students will specialize on a structure of a parallelogram as "component structure of a higher one, [...], and they will learn to recognize corresponding elements, by acquiring the structure of a technical language" (Dina van Hiele, in Fuys et al., 1984, p. 187). By this process, the students will construct the meaning of the rectangle as a specialization of the meaning of the parallelogram, incorporating the additional properties of the rectangle, which will be reinvented through the process; this means 'dynamically reinvented'.

Instumental path B: Construct a rectangles' axes of symmetry

In this phase the notion of symmetry is introduced by using the transformations of the rotation and reflection of the software. The recognition/understanding of the symmetry of geometrical objects is the fundamental aim of this study, in accordance with van Hiele's theory, as mentioned above.

Symmetry lines are those lines which the construction of the symmetrical point for any point on the figure leave the figure unchanged. I shall describe how the students construct the rectangle's symmetry lines (or axes of symmetry). This process helps students build the secondary properties of figures. In effect, the students must be led to investigate and locate those lines. In this case, the figure operates as the symbol [meaning, " $a$ mental substitute for a complex of undifferentiated relations that is subsequently elaborated in the pupil's mind" (Dina van Hiele in Fuys et al., 1984, p.215)] from which students shall produce the properties (van Hiele, 1986). The students will face difficulties in understanding the meaning of axis of symmetry and how it differs from rotational symmetry, which is expressed with the misunderstanding of the roles that the secondary elements (for example, the medians of a triangle or the diagonals of a rectangle) play in the figures' symmetry. Another point is students' difficulty in distinguishing the difference between the meanings of "symmetry of an object with regard to an axis of symmetry" and the meaning of "symmetry lines of the figure." The construction of the diagonals of the rectangle as rectangle's axes of symmetry is a commonly known misunderstanding faced by many students (e.g., Panaoura et al., 2009, p. 46; Patsiomitou \& Emvalotis, 2010). Through the current process the students pursue conquering the cognitive tasks:

- $\quad$ Correlating the construction process with the investigational part of the current phase and overcoming the conceptual obstacles correlated with the meaning of the axis of symmetry with the construction of the diagonals of the figure.

- $\quad$ Perceptually understanding the axis of symmetry as a result of the connection of the midpoints of the opposite sides of the shape and consequently to construct the meaning of the midpoint-parallel line. In other words, to dynamically reinvent a rule "the segments that join the midpoints of the opposite sides of the rectangles are its symmetry lines".

- $\quad$ Equating the two processes and consequently connecting the primary and the secondary properties of the shape.

- Defining the axis of symmetry of the rectangle and constructing a definition of the rectangle based on the definition of the axis of symmetry.

- Investigating and reasoning whether the axis of symmetry are perpendicular

\subsection{An excerpt of the research process}

Analysis of the process [324]: The student has set herself a goal and is now developing a subgoal. Her goal is to find "the rectangle's axes of symmetry". In other words, she may think the latter are the diagonals of the rectangle. There are two possibilities here:

--That she faces a misconception. 
--That she does not know how to instrumentally decode the figure's axis of symmetry.

If the latter is the case, she is facing an instrumental obstacle. I believe that this obstacle helped her to make numerous mental mind transformations, which she expresses at other points (further down) in the dialogue (point 326). It is not sufficient if she faces a misconception or she does not know how to construct the axis of symmetry in the figure.

Analysis of the process [325]: The student M8 is not able to positively identify the symmetry axes of quadrilaterals. She incorrectly believes that the notion of rotational symmetry 180 degrees coincides with the notion of reflective symmetry. An example of the research process includes the following discussion:

324. $\mathrm{M}_{7}$ : let's find the rectangle's axes of 325 . M M $_{8}$ What for?

symmetry. I know... I mean, we have to join the (M8 is wondering what the point in constructing the diagonals... diagonals is).

Figure 10a. Construction of the diagonals and the midpoint of the diagonals that dichotomizes them both.

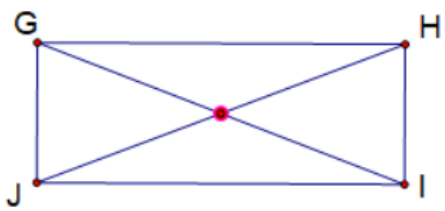

Instructing students in these two important notions-- rotational symmetry and reflective symmetry-- using static means does not help the students to exam the similarities and differences between the two notions (or to compare and contrast the two notions). The students find out that construction of the symmetrical point of a vertex yields a point not belonging on the figure. Probably for this, in [324], the student M7 initially constructs the diagonals as the symmetry lines of the figure. The construction of the symmetrical point of a vertex of the figure, selecting a diagonal of the rectangle as axis of symmetry leads the students to investigate the notion of the figure's symmetry by axis empirically and helps them to overcome the misconception (Figure 10b).

At this point an interdependence of the tools helps the students to overcome the misconception through the use of the vertical line and the reflection tool.

326. $\mathrm{M}_{7}$ : It will pass from this point (she is showing the intersection point of the diagonals), it must be parallel here (and points to JI) and pass from here (points to intersection point of the diagonals) ... and be vertical here (and shows towards $\mathrm{HI}$ ).
327. $\mathrm{M}_{7}$ is selecting the intersection point of the diagonals, then the segment HI, and then considers selecting the intersection point again and chooses the perpendicularity command from the menu.

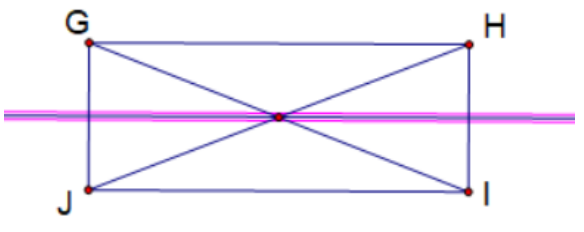

Figure 11. Construction of a line parallel to JI

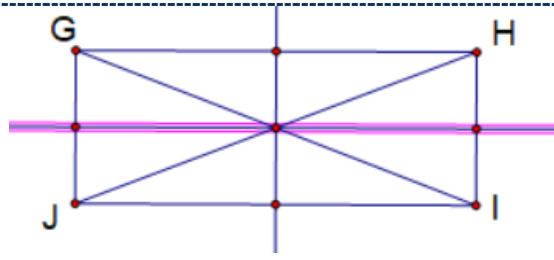

Figure 12. Construction of a line vertical to HI.

Analysis of the process [326]: M7 is submerging in her thoughts and continues by expressing an anti-economic element (as to where the perpendicular will be parallel or vertical). Moreover, the student shows that she has managed to connect the construction of the parallel line to the theory underlying the construction, since she is led to a verbal formulation which contains both the point and the line to which she will construct the perpendicular, in other words she has constructed the meaning of perpendicularity. In other words, at this point she instrumentally decoded the construction in her mind and developed the place way, the verbal and the sequential apprehension of the figure. Yet, it still shows that the student has formed the connection between the notions of 
perpendicularity and parallelism.

Analysis of the process [327]: Although the students do manage to draw the figure, the construction does not serve as an indication that they have the competence to generalize the construction or the hypotheses conclusions they have been led to make.

As a result, the students remain in a state of disequilibration, evident in the discussion that follows. In [327-328], M7 is either led to anti-economic actions while trying to construct the perpendicular, or condenses necessary actions. These actions are connected to M7's verbal formulation in [326], thus reinforcing the opinion about the perturbation observed at this specific stage of research.

\begin{tabular}{|c|c|}
\hline Dialogue & Analysis \\
\hline $\begin{array}{l}\text { 328. Then selects } \mathrm{JI} \text { and the perpendicularity } \\
\text { command from the menu. }\end{array}$ & $\begin{array}{l}\text { M7 selects the line JI but not the point through which she can } \\
\text { draw the vertical line and parallel to HI. }\end{array}$ \\
\hline 329. $\mathrm{M}_{13}: \ldots$ and the center (for selection) & $\begin{array}{l}\text { M13 has constructed the instrumental decoding of the } \\
\text { construction of a perpendicular line through the cooperation } \\
\text { with his schoolmates during the research process. }\end{array}$ \\
\hline $\begin{array}{l}330 . \text { R: Are GI and } \mathrm{HJ} \text { the axes of symmetry? } \\
331 . \mathrm{M}_{7}: \text { No }\end{array}$ & I was not sure if they had understood it. \\
\hline 333. $M_{8}:$ Why do we need two [axes]? & $\begin{array}{l}\text { Another point of misconception. The student thinks that there } \\
\text { is only one axis of symmetry. }\end{array}$ \\
\hline 334. $\mathrm{M}_{7}$ : Yes, it has two axes of symmetry & $\begin{array}{l}\text { This is a point crucial for the research as M7 has she has } \\
\text { conceived the notion "a rectangle has two axes of line } \\
\text { symmetry", during the development of instrumental decoding. }\end{array}$ \\
\hline 346. $\mathrm{M}_{7}$ Lets join the midpoints & $\begin{array}{l}\mathrm{M}_{7} \text { constructs the symmetry axes joining the midpoints of the } \\
\text { opposite sides of the rectangle }\end{array}$ \\
\hline
\end{tabular}

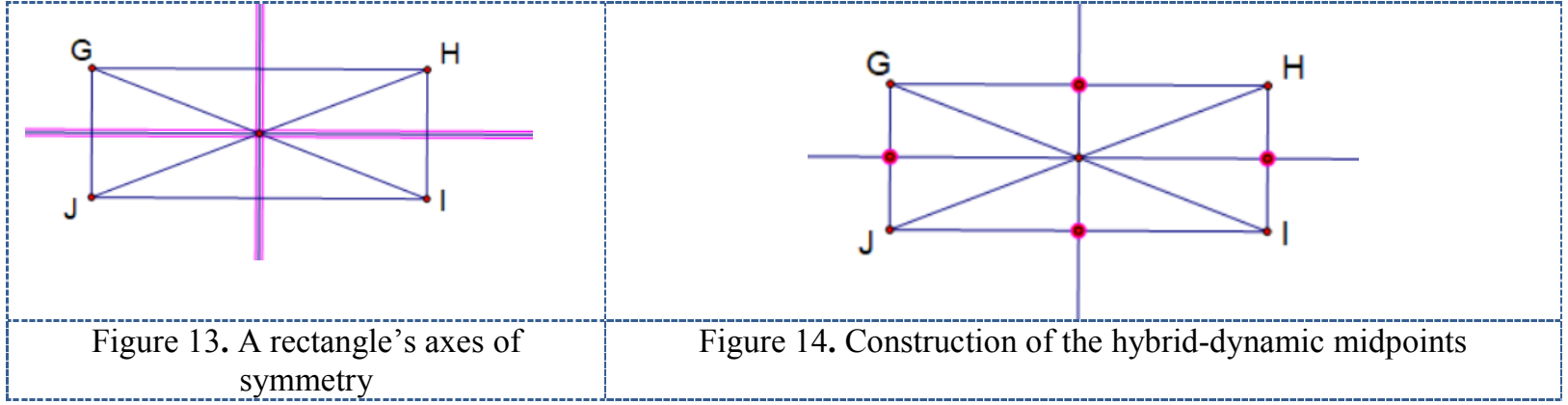

$\mathrm{M}_{7}$ is led to correlate the notion of perpendicularity from rectangle's symmetry centre to that of its interparallel (perpendicular bisector); namely, she correlates primary and secondary properties of the rectangle. In this way, the student assimilates both meanings, i.e., that the interparallel lines are perpendicular to the sides. However, the students' understanding of symmetry in relation to a given axis is still incomplete, as is demonstrated in the discussion.

Interdependence of the tools: She is constructing the symmetry lines (a) joining the midpoints of the rectangle's two opposite sides (b) constructing the vertical lines. By constructing the symmetry axes in another way (joining the midpoints of opposite sides), M7 demonstrates her understanding that a perpendicular constructed from the symmetry centre crosses the middle of the sides (Figure 13, 14). The diagram on screen facilitates her construct that connection. Therefore, we have a theoretical construction result which derives through interaction with the on-screen diagram (Figure 15).

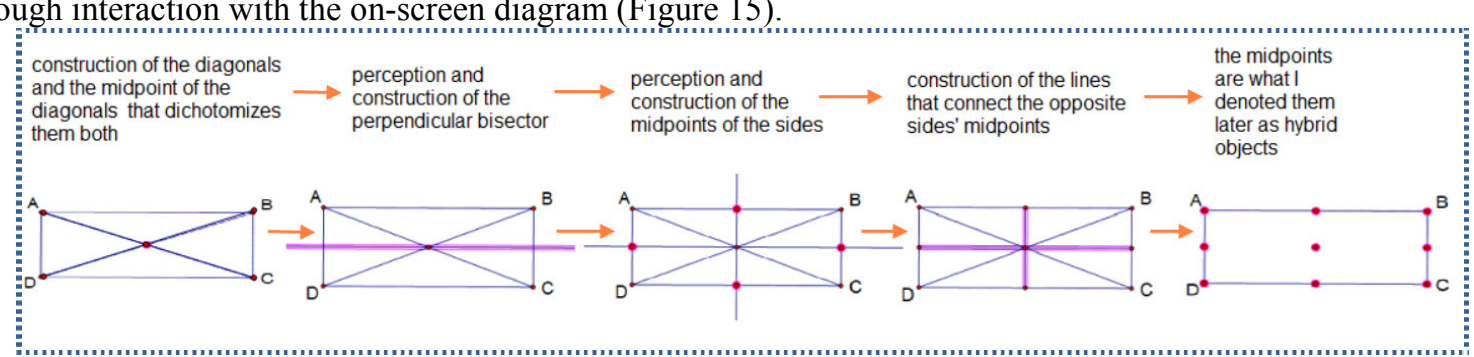

Figure 15. An instrumental learning path with sequential interdependences of the dynamic tools.

Analysis of the process [354]. Another crucial point for the student M7 and the whole team. She explains: "Here, (she points to the midpoints of the sides), midpoint, midpoint, midpoint, midpoint!"

The hybrid -dynamic objects, which represent the midpoints of the rectangle, impact significantly on the 
development of economic actions during instrumental decoding. I depicted the crucial aspects of the research process in the figure below (see, Patsiomitou, 2008d, in Greek). I used it to support the modelling process (e.g, De Corte et al., 2000) of my study. In other words, it is a modelling process through an instrumental learning path, connecting the primary and secondary properties of the rectangle.

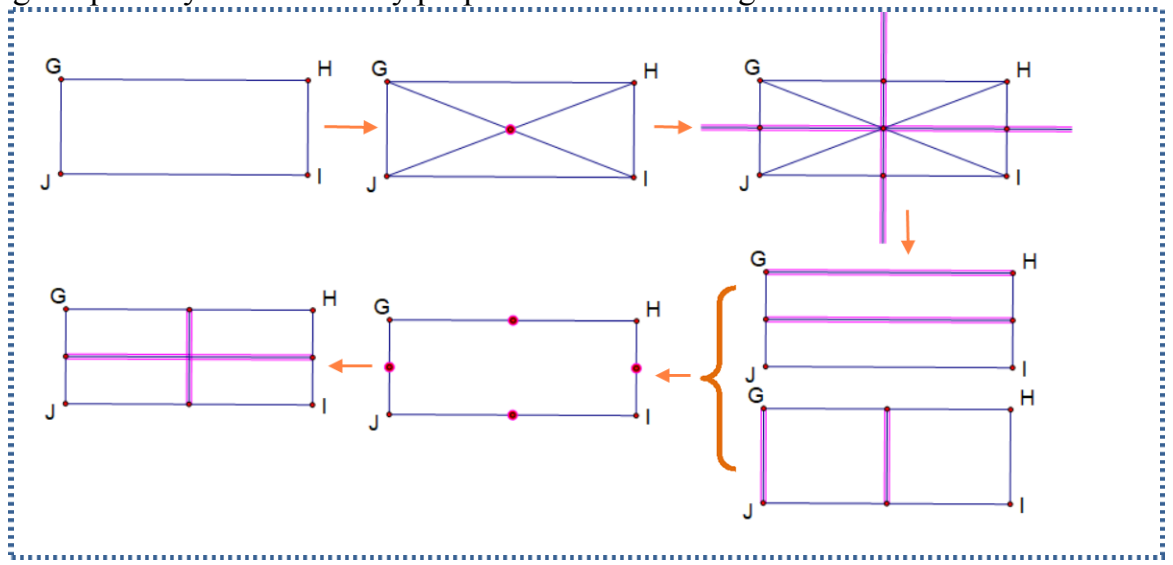

Figure 16. An instrumental learning path connecting the primary and secondary properties of the rectangle

M7 and the whole team have developed an abstract process in interaction with me and the software tools. This is what I called later a dynamic reinvention process (Patsiomitou, 2012a, b). During the dynamic reinvention of the construction of the axes of symmetry they understood that (a) there are two ways to construct the axes of symmetry, (b) there is a connection about actions and geometrical processes, (c) there is a connection between the properties of the figure.

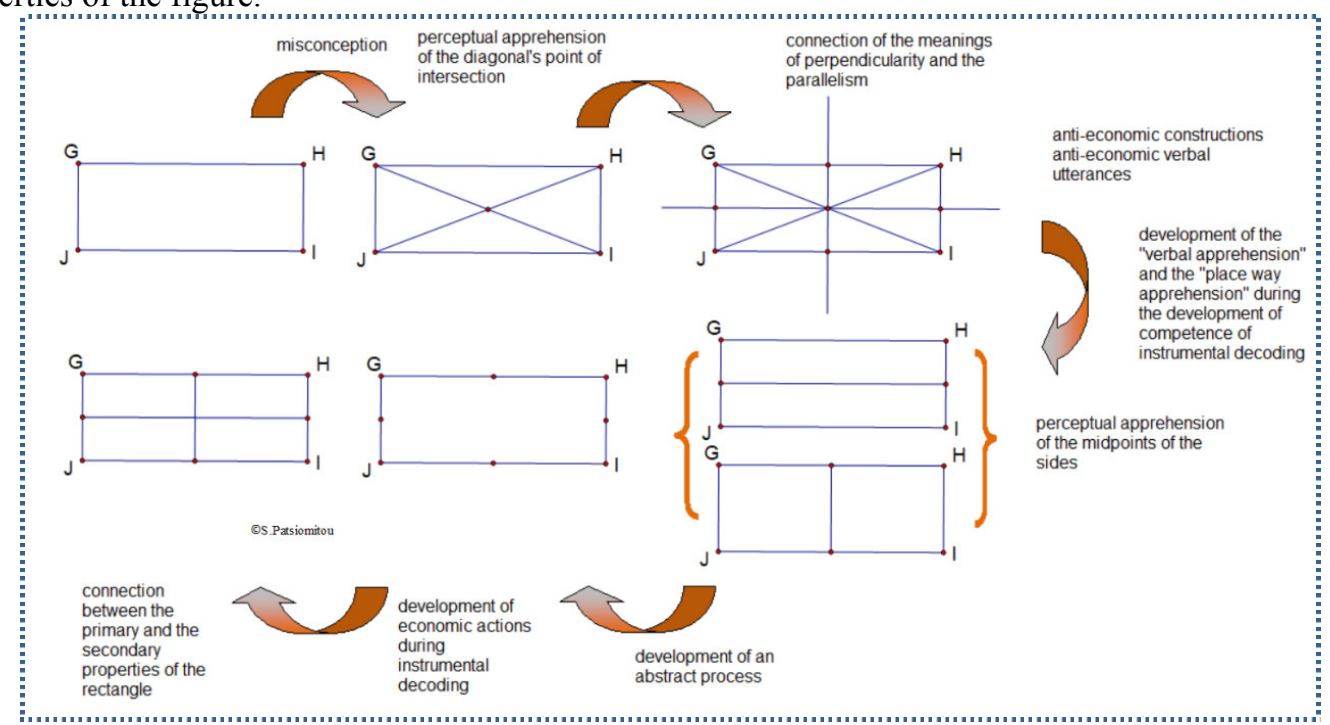

Figure 17. Interdependencies among student's use of tools and meanings: a cognitive analysis (see also, Patsiomitou \& Emvalotis, 2010)

Therefore, we have a theoretical construct derived through interaction with the on-screen diagram. M7 related the reflection of the objects with the symmetry by axis, meaning that she related procedures with meanings. Meaning the linking representations that she created during the process helped her to correlate the primary and the secondary properties of the figure, meaning the notion of perpendicularity to that of parallelism. In this way, the student assimilated that the interparallels are perpendicular to the sides. Consequently, the construction of the meaning, "the axes of symmetry are the lines that join the midpoints of the sides of the figure," is a result of this process. My aim was the students to construct the rectangle's symmetry lines (or axes of symmetry) as this process would help the students to construct the secondary properties of figures. As we can see, process B (i.e., lines joining the midpoints) is more abstract than process A, given that the construction requires fewer steps. Moreover, students have to know the underlying theory regarding the lines joining the midpoints (e.g., they are vertical to the sides they join and parallel and congruent to the sides they do not join). For this the competence to utilize the midpoint tool is important for the development of the students' thinking. 


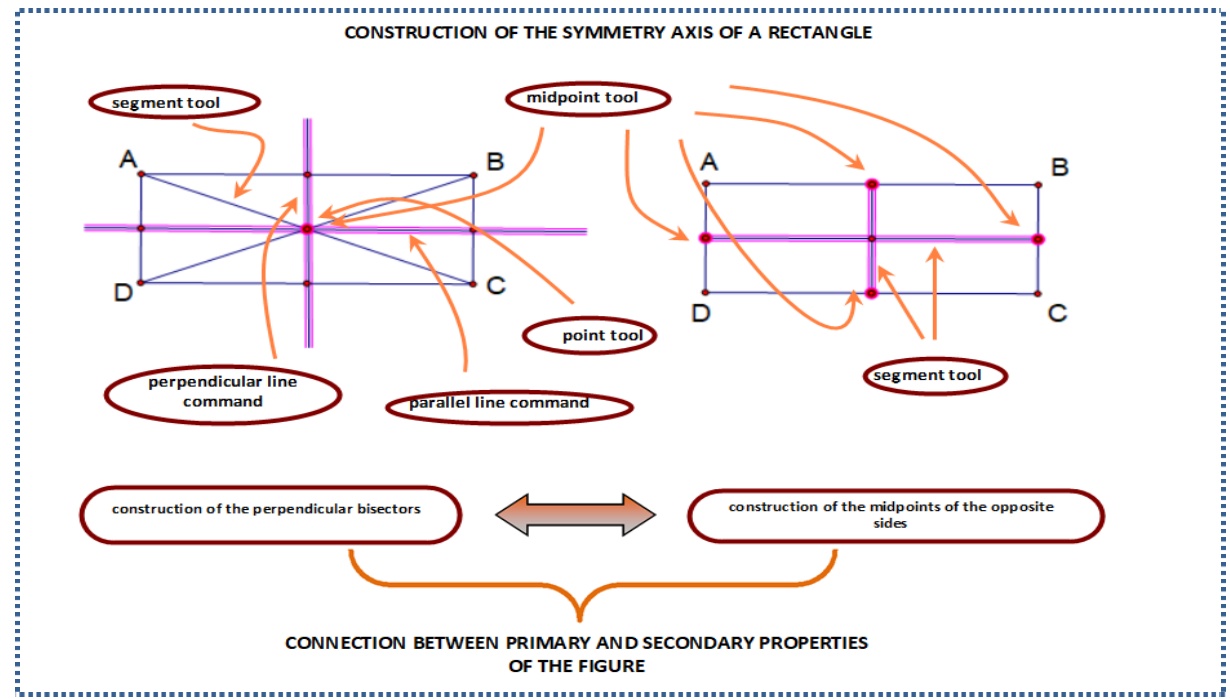

Figure 18. Connection between the primary and the secondary properties of the figure

Instumental path C: Construction of the custom tool "symmetrical point by center"

The whole process got me thinking and formulate a research question: Could the students develop the construction of the rectangle from the inside? Meaning could they use the figures' secondary properties to construct a quadrilateral by reversing the process they have followed until now? These thoughts led me to create a "S.M.A.R.T" tool (i.e., Simple, Multiple use, Active/Alive, Reversing use, Tool) (e.g., Patsiomitou, 2006a, 2012a, b, 2018).

I created the custom tool to help students visualize the meaning of central symmetry in correlation with the meaning of a segment's midpoint. Moreover, my aim was to facilitate students' construction of the symmetrical point by center, by condensing actions. This was very crucial for the evolution of the construction of a parallelogram through its diagonals.

The construction of the tool is very simple (Fig. 19), but it had a crucial effect on the development of the students' thinking (Patsiomitou, 2012a, b; 2018). The idea of creating the concrete custom tool occurred after creating a similar tool to construct the "golden ratio" (Patsiomitou, 2006a, 2018, 2019b). If my students implemented it on screen, they could view a segment with its midpoint.

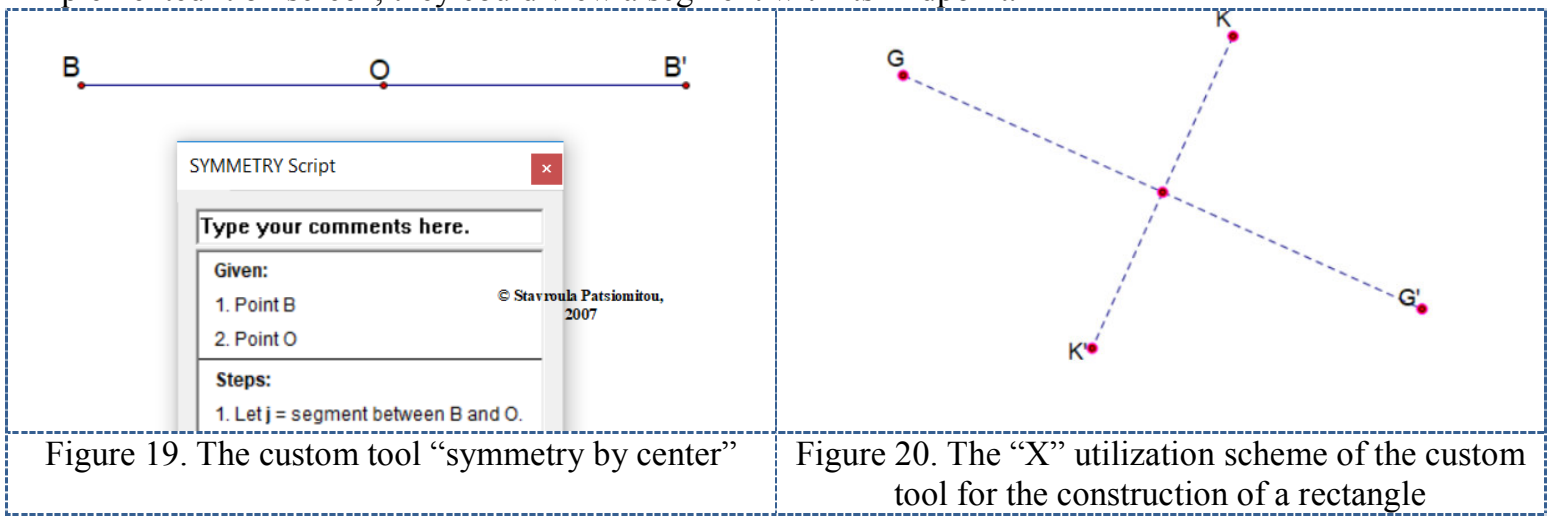

This tool helped them connect the meaning of symmetry by center with the meaning of a segment's midpoint. If they applied it twice on a point $\mathrm{F}$, they visualized an " $\mathrm{X}$ " symbol which students view when constructing the diagonals of a parallelogram. Fig. 20 illustrates an implementation of the custom tool once on screen. The original point of the tool application is the point whose symmetrical we wish to construct by another point, which is the symmetry center and the second point of the tool's application (Figure 20). When the tool is applied to two points, point A and the symmetry centre, the point symmetrical to A (namely a third point marked A') is produced, as well as the lines connecting the points. 


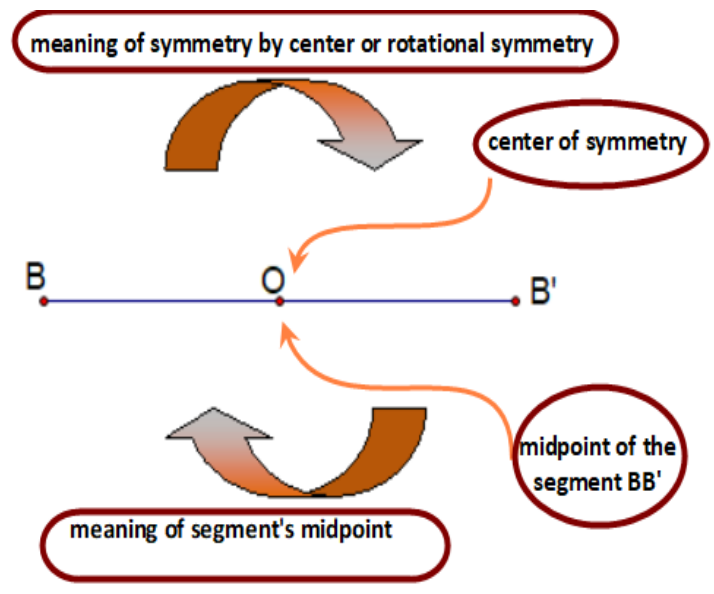

Figure 21. Interdependence of the tools and connection between meanings

In Fig. 20, the modification of the angle between the segments $\mathrm{GG}^{\prime}$ and $\mathrm{KK}^{\prime}$ and the length of the segments determines the kind of parallelogram produced/generated (e.g., Patsiomitou, 2012b, p.72). Firstly, a student-user assimilates the meaning incorporated in the use of the tool into his preexisting knowledge (for example, s/he connects the meaning of the symmetry by center with the meaning of the segment's midpoint). S/he may then face an obstacle (an instrumental obstacle) (Patsiomitou, 2011, p. 362) with regard to the use of the tool.

I distinguished a few types of instrumental obstacles due to student lack of competence in instrumental decoding. For example, the tool cannot be applied on a segment to find its midpoint. This occurs because I created the tool with concrete properties to incorporate the meaning of rotating a point by 180 degrees. This assumption generates a cognitive conflict in the student. The students used the tools efficiently or in an economical (/ catachresis) mode (Rabardel, 1995). In the current study, I shall present the impact of the custom tool on students' thinking, as well as the development of their abstract thinking, the recognition of instrumented action schemes through the emergence of theorems and concepts-in-action and the verbalizing of concepts during the process. The problem I posed the students was this: Can you construct a rectangle using the properties of its diagonals? My aim was for students to construct and connect the notion of symmetrical points with the meaning of the segment with double length from the original segment (Figure 21). Applying the custom tool to point $\mathrm{O}$ produces a segment whose midpoint is point $\mathrm{O}$. But this same point $\mathrm{O}$ has another, complementary role: it is the center of rotation for the construction of symmetrical point $\mathrm{B}^{\prime}$. Using the tool helps students understand the dual role of point $\mathrm{O}$, as well as the connection between the meanings "symmetry by center" and "midpoint of the segment". 


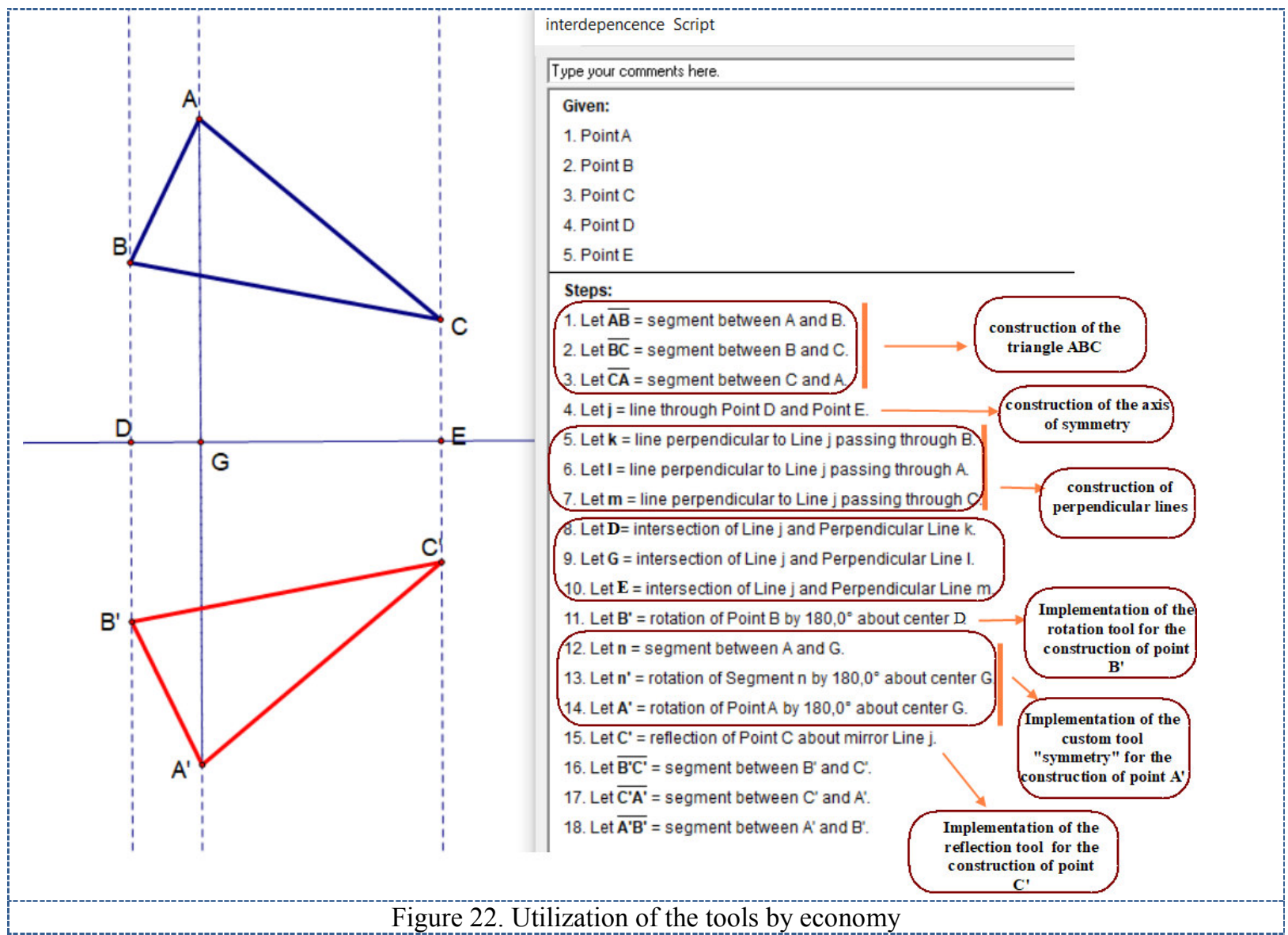

Intra-dependence of the tools: Then the students used the custom tool by economy. When I asked them to identify the symmetrical of the triangle $\mathrm{ABC}$ using as symmetry axis the side DE, student $\mathrm{M}_{13}$, who is familiar with the use of the tool, since he had already used it several times in this particular phase of the research, does not use some other tool. He chooses -surprising me- the custom tool using it as described below, by economy. He selects the vertex A as the first point and point $G$, as second point and applies the tool: namely, he constructs the symmetrical of point A by point $\mathrm{G}$, in order to reflect it (Figure 22). The students aim was to construct a symmetrical triangle by axis. Consequently, even though the student assimilates the use of the tool in order to construct a figure the tool was not appropriate to produce, there is a logical connection between the student's actions and the software, through geometrical theory. Then the group has constructed the triangle $\mathrm{A}^{\prime} \mathrm{B}^{\prime} \mathrm{C}^{\prime}$ using the reflection tool. In the discussion that follows, one may discern the difficulty the students have in constructing symmetry by axis. The construction of the symmetrical triangle by axis was implemented by students using the tool. So, they constructed the triangle A'B'C' using three processes.

Through visualization of the reflected object, students are initially led to use empirical methods (such as measurements) in order to confirm that symmetrical objects (objects produced by reflection) lie at an equal distance from the axis of symmetry. This action leads the student to construct an instrumented action scheme, related to the reflected object on screen. 


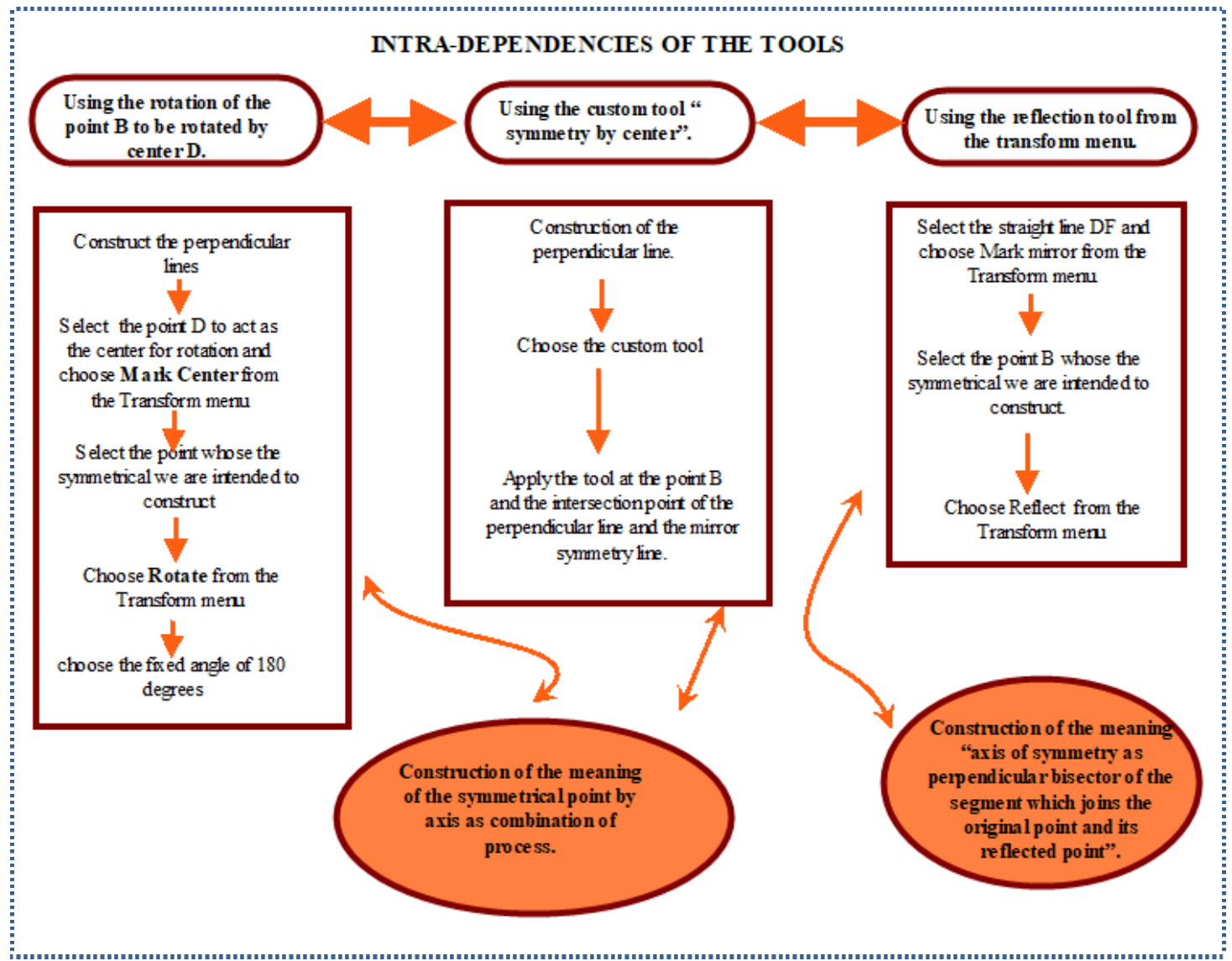

Figure 23. The intra-dependencies of the tools

Moreover, the students can connect the theory of symmetry by axis in static means with the object's reflection in a DGS environment. Their actions are an identification that they are trying to adapt the cognitive scheme they possess (regarding symmetry by axis in static means) to their software constructions, using the custom tool. In this case, the tool has an auxiliary function in facilitating knowledge construction as it "cooperates" with the students facilitating the accomplishment of their goal.

In the figure 22 , I reconstructed the symmetrical of the triangle ABC using as symmetry axis the side $\mathrm{DE}$ (and saved it as custom tool). As it is illustrated in the script, I used three different processes for the construction:

- the rotation tool for the construction of point $\mathrm{A}^{\prime}$,

- the custom tool "symmetry by center" for the construction of point B', and

- the reflection tool for the construction of the point $\mathrm{C}^{\prime}$.

Despite the inappropriate use of the tool, the construction result is visually correct. I implemented the custom tool "symmetry by center" to the points A, G and the rotation tool to the points B and D, with efficiency or in an economical mode. This action led me to think the intra-dependencies of the tools as they are reported in the figure 23.

Instrumental path D: Construction of the rectangle using the figure's symmetry properties

The students' task is to construct a rectangle based on the figure's symmetry. The group attempts to find a way to construct the figure and various strategies are proposed. $\mathrm{M}_{8}$ considers constructing the figure through the use of a right triangle, which he constructs on-screen differently from that conceived by $\mathrm{M}_{13}$. The students know that a diagonal in a rectangle separates the rectangle into two right triangles. She builds on this to develop a strategy which continues the process. Moreover, she has also "mereologically" perceived the figure. The Greek word for 'rectangle' is 'orthogonio (parallelogram)', which is similar to the Greek word for 'right triangle', which is 'orthogonio (triangle)'. The student has obviously confused the two; what she means is: "The rectangle has two right triangles (as opposed to one)". The students perform mental transformations which anticipate precede their software constructions. According to Simon (1996), they develop transformational reasoning, which assists them in anticipating their following actions. This process is initially carried out mentally and concerns the object's transformation, in order to produce a solution to the problem. 


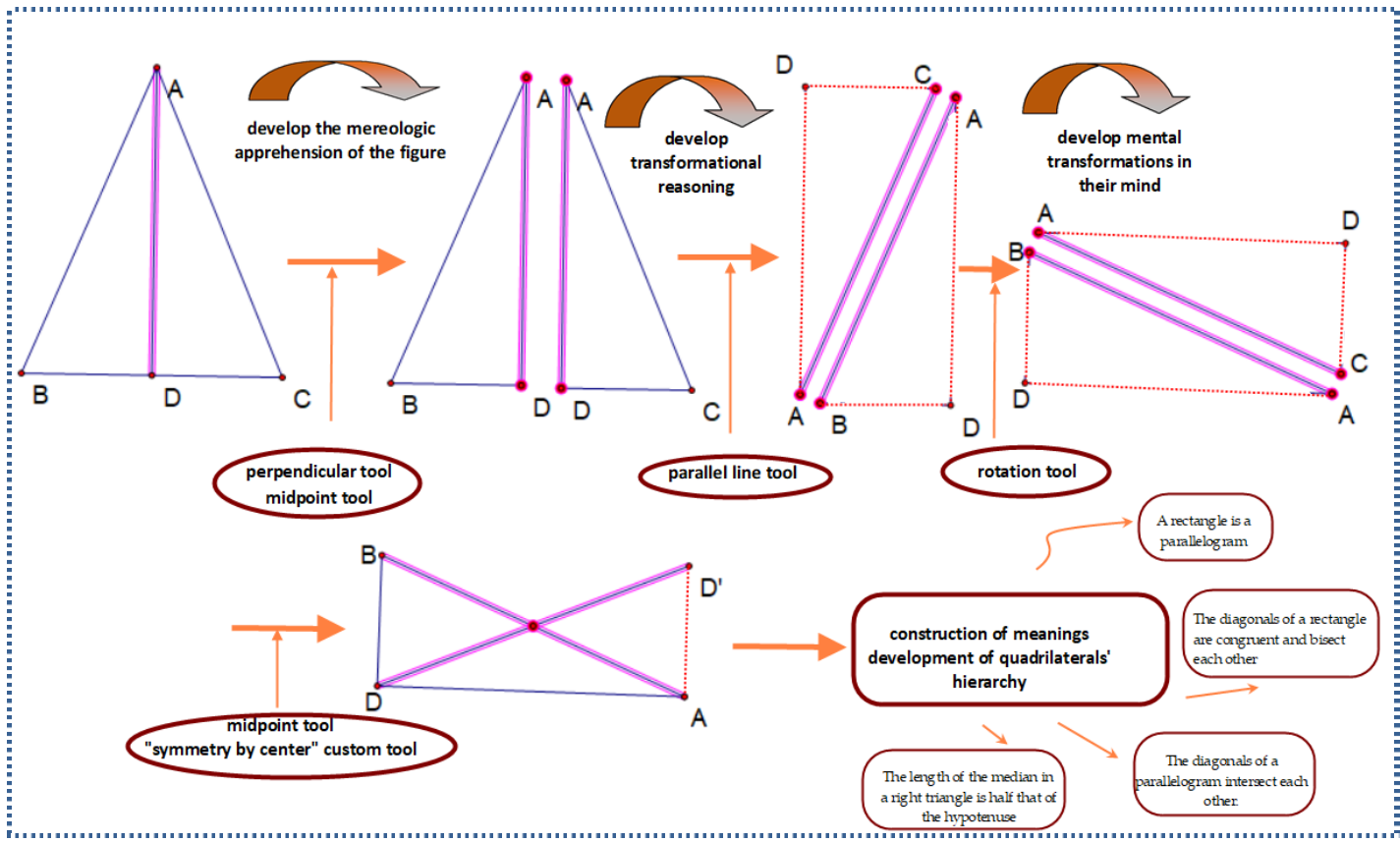

Figure 24. An instrumental learning path for the construction of a rectangle

$M_{13}$ instrumentally decodes a figure according to his mental image, with the use of the tool. The construction of the right triangle starts with the random construction of a right angle by the student who conforms only to visual constraints. $\mathrm{M}_{13}$ had a sequence of thought without the student being focused to do an accurate construction process. $\mathrm{M}_{7}$ has entered $\mathrm{M}_{13}$ 's universe of thought related to the rectangle construction strategy as she suggests the student apply the tool on the midpoint of the hypotenuse. In this way, $\mathrm{M}_{7}$ has connected the notion of the bisection of the diagonals and the theorem relative to construction of a right triangle, but she does not formulate this verbally. The students construct the rectangle according to the figure's symmetry properties. Therefore, we are led to consider that the dynamic transformations applied by the students in previous stages of the research process led them to acquire figure's symbol character transforming it into signal character (van Hiele, 1986). According to Sang Sook Choi-Koh (1999) "when symbols influence orientation of thought they act as signals" (p. 302). More specifically, M7 knows that the diagonals of a parallelogram bisect each other. This process leads them to comprehend that "the length of the median in a right triangle is half that of the hypotenuse". When $\mathrm{M}_{7}$ applies the tool, the segment formed is double the length of the median therefore is congruent to the hypotenuse, which is also the other diagonal of the rectangle. Figure 24, above analyzes students' actions.

From the part of the research mentioned above, we can see that the design of instrumental learning trajectories created in a dynamic geometry environment can improve students' knowledge. Consequently, the design of efficient instrumental learning trajectories and the ways these trajectories are integrated into the teaching process is the most important thing for the learning of mathematics.

It is taken as granted, these days, that software can be used in many different ways, and that it is the actual use of the tool (i.e., the curriculum, the learning tasks, the instructional methods) that can have an impact on learning. However, in these excerpts of the research process, I can talk about, how a "piece" of software impacts students' thinking.

\section{An instrumental learning trajectory for the construction of regular polygons through the use of transformations}

Research methodology: 25 students participated in the learning process. They were all in the first year of secondary school, aged 12-13 years, and were at a level above the average for that year. More specifically and with regard to mathematics, this was a conclusion I reached in the light of (1) the level of the students' answers to questions posed during classroom teaching, (2) the results of the quarterly exams / assessment, (3) their rate of participation in answers and (4) my own mental comparisons at different teaching stages and phases with the performances of other classes. I taught the students Mathematics using traditional means: i.e., rule and compass, but also used dynamic geometry software with the same meanings near simultaneously, on an interactive whiteboard. The children were enthusiastic about the application of the meanings on the interactive whiteboard, using dynamic geometry software. The students participated during the teaching process, or outside the classroom during the home learning process, using all the tools both static and dynamic, but also the electronic classroom that I had created in a Moodle (Modular Object-Oriented Dynamic Learning Environment) 
environment (Dougiamas et al., 2003) to help them understand the teaching material and form mental representations, which is especially important for developing their problem-solving ability and level of mathematical thinking.

The activities I created in the software and then posted in the Moodle environment were the same activities I had planned to use for teaching, but also others which I improvised during the lesson in response to my students' needs, constantly designing and redesigning the lesson activities in the light of the feedback I received from their answers.

The transformation menu of the dynamic geometry software [e.g., Geometer's Sketchpad, GeoGebra] was used for the constructions. The students were taught the concepts of reflection and rotation--which are not taught in a traditional mathematics class--in parallel with the concept of symmetry, enabling them to connect the two processes by which the concepts can be created conceptually and procedurally (Patsiomitou, 2012a, b). Usually, the concepts were approached from a historical point of view. For example, I had taught the concept of equilaterals during a discussion with students about the ancient text in Euclid's Elements, Book I, Proposition. [1] (Stamatis, 1957). The problem I had posed in order to evaluate their understanding was the following (Patsiomitou, 2015, p.225, 2020a, in Greek)

Problem: Cooperate in groups and construct a regular polygon or a kite using every tool you think is appropriate (static or dynamic). Your construction should not be the same as the construction of the previous group. p.s. The answers will be posted in the Moodle environment [in a Wiki]. Please read the previous posted construction.

The students had divided in six groups, following the Jigsaw model (Aronson et al., 1978). If we analyse the process with the Toulmin pseudo-model, which describes the use of tools, the theorems that students are aware of and what they imply (e.g. theorem T2, which is connected with a dotted line) and which are not clear from the description they give, we observe that connections are made between the concepts and actions through the use of tools between the students' groups, due to the sequential order in which the method and the feedback the next student receives when reading the method of the previous student are posted.

Moreover, we observe the interdependences among the tools of the construction in each group and the intra-dependences among the tools of all the groups. The figure 25 is a diagram in which we can view the inter/intra dependences among the tools and the meanings, as they have developed among the six groups. It is an instrumental learning trajectory with many different paths.

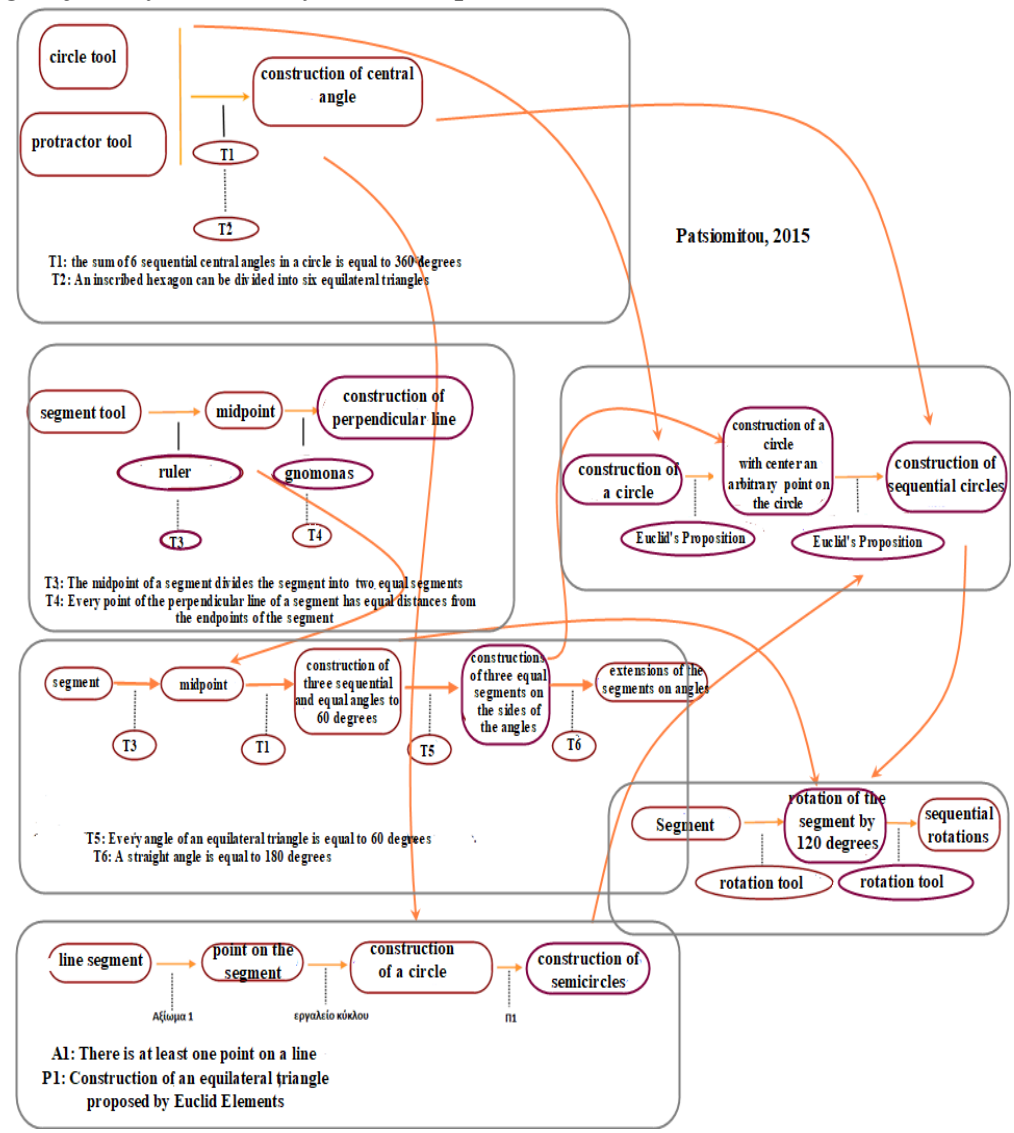

Figure 25. Inter and Intra-dependencies in an instrumental learning trajectory (Patsiomitou, 2015, p. 232, 2020a, p.121) 
Analysis of the process (group 1): The group builds a hexagonal regular polygon using static means. They do not list the tools they use, but they describe their actions accurately. The polygon is constructed using central adjacent angles of 60 degrees. For this, I concluded that they are using the protractor tool to construct six central adjacent angles whose sum is 360 degrees (a circle). As it is obvious, from this construction process the group knew that the full angle of a circle is equal to $360^{\circ}$ and that each side of a regular hexagon inscribed in a circle is a chord of a circle with a corresponding central angle equal to $60^{\circ}$. Turning now to the construction process in the classroom using dynamic geometry software, the group seems to have instrumentally decoded it correctly, since they were able to understand that constructing a rotation in the software with a $60^{\circ}$ angle is, as a process, a translation of the use of protractor in static means.

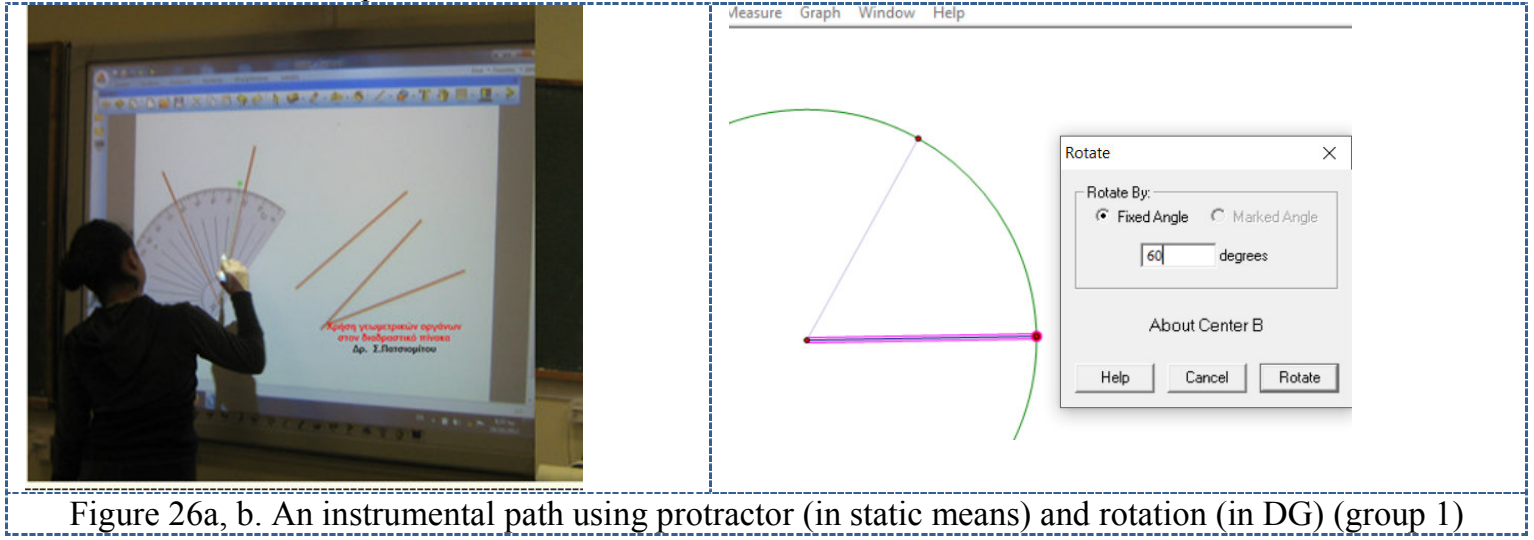

Analysis of the process (group 2): The next group describes a rhomboid kite. The group's description is general rather than specific, meaning that they do not mention tools, so I do not know if they built their kite using static or dynamic means. In discussion with the group expert, he told me that it was a construction in the dynamic geometry software, which they subsequently repeated in a paper-pencil environment. It is also obvious that the group has made the connection between the process of perpendicularity using the static and dynamic tools respectively, as well as the property shared by every point on the perpendicular bisector of being equidistant from the ends of the segment.

Analysis of the process (group 3): The next group describes a construction related to the construction of the first group. However, it differs from the previous groups because this group does not use the compass, only the protractor and the ruler. The construction is completed with extensions of segments parts. Completing the construction therefore implies different theorems and indicates a procedural understanding of the shape's symmetry procedurally.

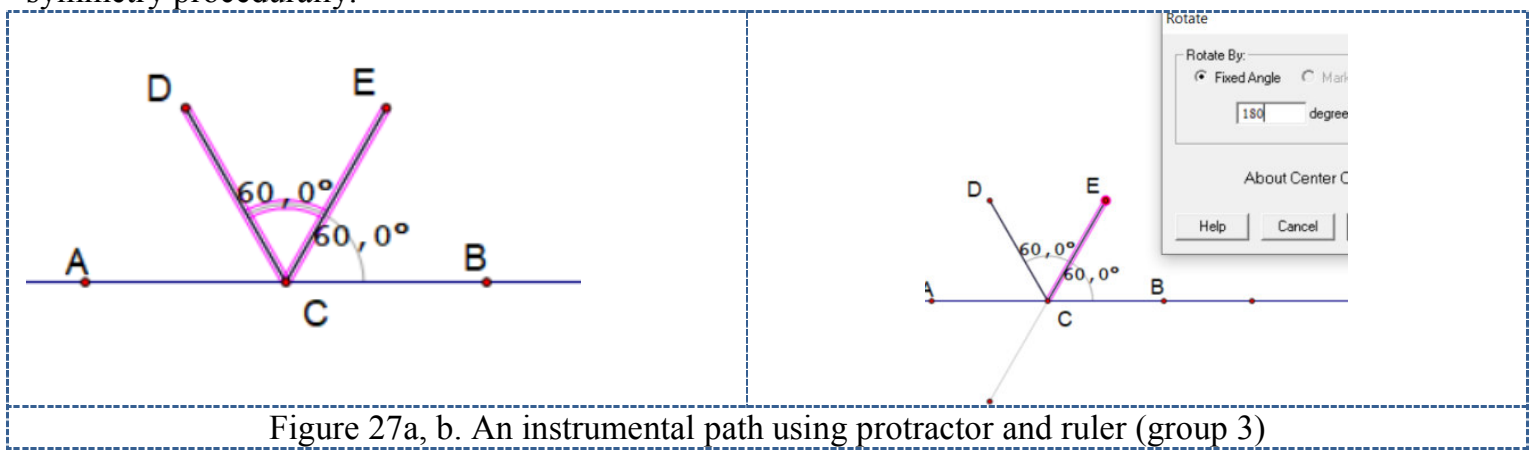

Analysis of the process (group 4): In the next construction, the group uses only the compass tool to build a hexagon. Their hexagon was constructed in the dynamic geometry software and the decoding of the construction is done using static means and with appropriate terminology which uses elements in economy (for example, students construct semicircles and not circles). This time, the ruler tool plays a purely auxiliary role. The students' construction reveals that they have made important connections between concepts. It also shows that the students in the group have made important progress towards developing the ability for abstract thought which is required for a higher-level study in geometry. 


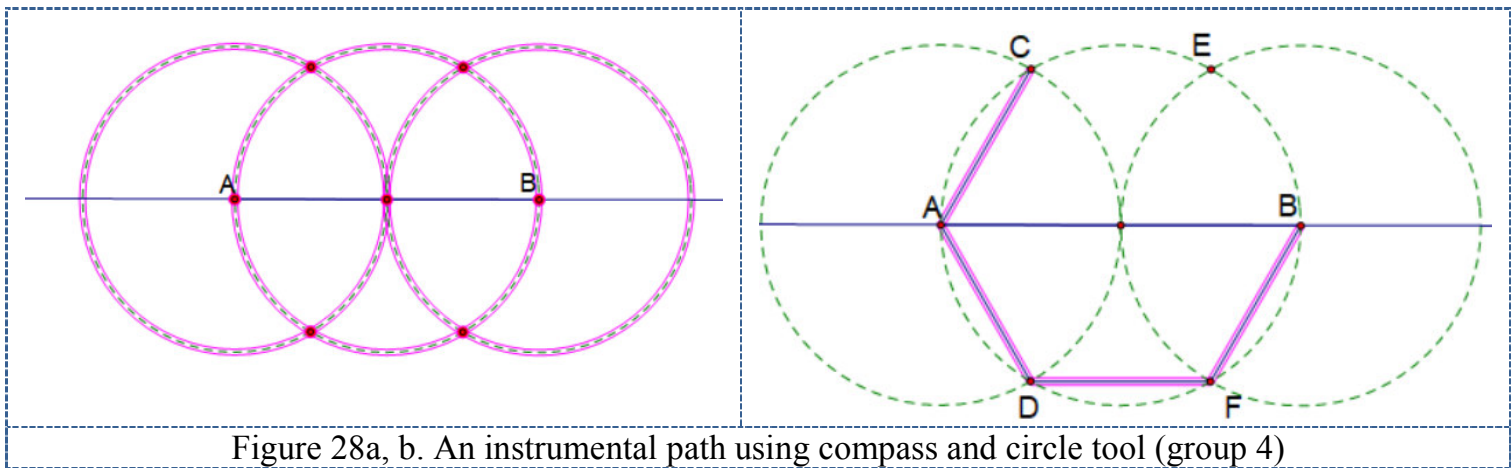

Analysis of the process (group 5): The group uses only the circle tool and implies the Proposition 1 of Euclid's Elements [which they were taught] to construct the process. They also construct a hexagon out of a series of equilateral triangles. Their construction is different from those of the previous groups, but uses elements used in previous constructions. It was worked on entirely in the dynamic geometry software and describes their actions, by instrumentally decoding those using verbal formulations.

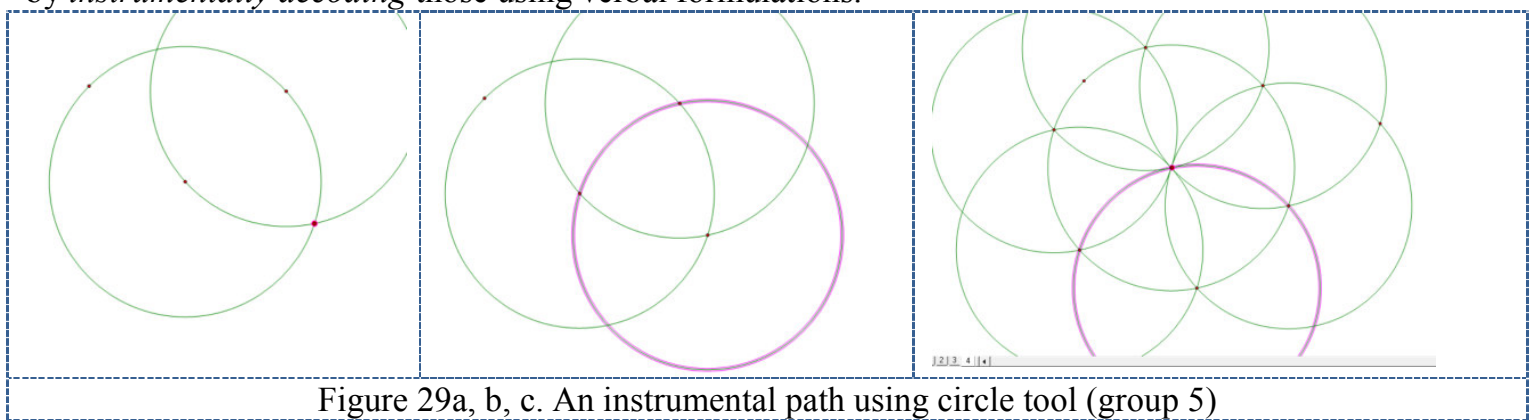

Analysis of the process (group 6): The next and final construction is performed entirely using the transformation tools provided by the dynamic geometry software. The group uses transformation tools to build the hexagon. By rotating the straight segment through 120 degrees, the group is clearly employing the theorem that determines the angle of each polygon. They then connected segments without exploring why they meet at the same point, explaining that the shape consisting of the six equilateral triangles is what is required. Obviously, the construction process implies that the group's level of geometrical thinking is high for their age and year. I concluded this in the light of the specific construction process the group used, but also and more significantly because their responses and actions were made spontaneously in class.

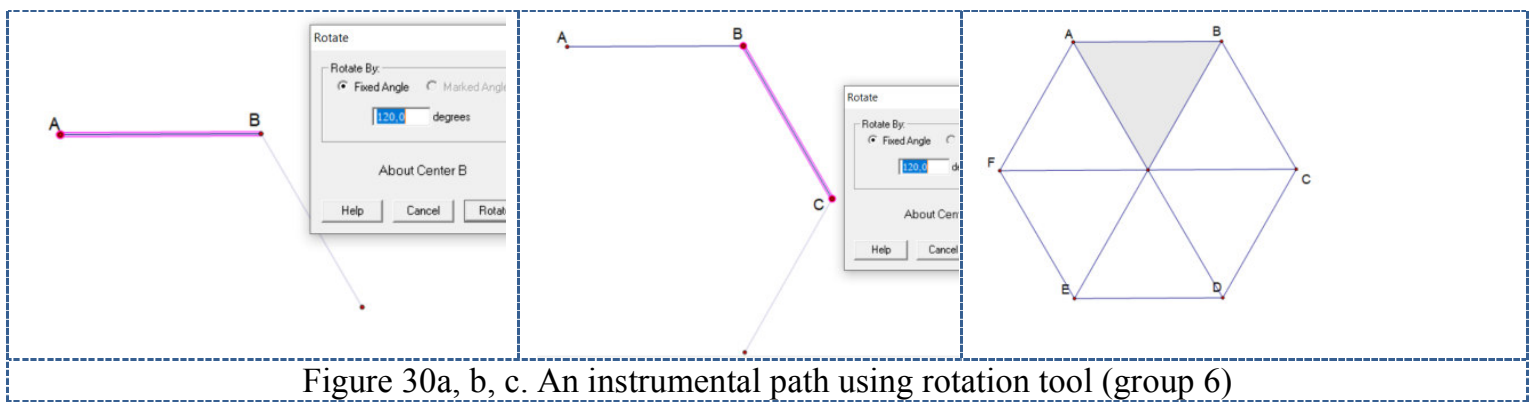

\section{Developing a theory on dynamic transformations}

In my study "Students' learning progression ....") (Patsiomitou, 2014, p.30), I have discussed several kinds of transformations and transformational results that ensue from implementing dragging on screen (Patsiomitou, 2019 b, p. 43-44). Transformations used by the students in the DGS environment can be distinguished through the following.

\subsection{Transformational result of an object due to dragging}

I have distinguished three cases of the transformation of geometric objects due to dragging (for example, the transformation a rectangle can undergo as a result of one of its vertices being dragged on screen) (Patsiomitou, 2019a, b, c): 
- The object (e.g., a rectangle) remains unmodified in terms of its structural features, but a magnitude of one side is modified on the screen due to the way it is constructed (visual mode of transformation) or its orientation changes (place way or positional mode of transformation).

- The object is "messed up" because it has not been constructed in a theoretical way (meaning the user has developed only his/her perceptual understanding). When the reconstruction is performed in a theoretical way, the construction remains stable (reconfiguration of the figure in a mereological way)

- The object is dragged unmodified on screen as a hybrid object due to the dependence of the point being dragged on other geometric objects in the diagram.

The three cases of object transformation may have occurred due to the user's intent on theoretical (the student aims to transform a drawing into a figure on screen, meaning s/he intentionally transforms a drawing to acquire additional properties) or experimental dragging (the student investigates whether the figure --or drawing-- has certain properties or whether the modification of the drawing in the picture plane through dragging leads to the construction of another figure) (Patsiomitou, 2011, p. 362).

\subsection{Combinations of transformations due to combinations of techniques}

The type of transformation due to dragging can be combined with other techniques to bring about a combination of on-screen transformations, such as:

- $\quad$ Dragging and tracing of a geometric object (for example a point, segment or line)

Dragging a point on screen results in the transformation of its position and the simultaneous appearance of traces on screen tracking the path the point has followed or the tracks that a line passes due to dragging transformations. This action reveals in the determination of a basic property of the diagram that cannot be directly perceived from the diagram in its hybrid form, or a property of the diagram that remain stable and unaltered.

- Dragging and measuring (or calculations) the geometric object.

Dragging a point on screen leads to a change in the measurements of the object, which we have chosen to display and in its calculations. In this case, the measurements are modified, but the calculations may do one of two things: they may remain unchanged, indicating a stability that demonstrates the validity of a theorem or general theoretical approach (a proposition or a confirmed theorem --meaning a conclusion or an inference) or they may change, allowing the user to observe and draw conclusions from empirical results.

- Dragging and animating, or dragging, animating and tracing objects

For example, dragging a point (on the vertex of a triangle, for example) which is connected by animation. The animation of the diagram and the simultaneous dragging allow us to understand a condition which is not defined during the diagram's structuring process. For example, it may make us aware of a theoretical constraint that has not been determined or established before, but which appears on the diagram when it is dragged. This condition leads into an investigation of the validity of a theorem or proposition.

\subsection{Transformation due to rotation}

The transformations used in the dynamic diagrams in this study were:

- axial symmetry (reflection);

- $\quad$ rotation, which results in the image of an object rotating at a predetermined angle, around a point, the center;

- translation, which results in the image of an object which is translated according to a specific vector. [e.g., I used it for the design of the guided orientation phase of the LVAR (Patsiomitou, 2008b, 2010)].

Rotation is the transformation of an object created in the software interface that results in the turn of the object with respect to a point (center of rotation) and to a specific angle (the angle of rotation). Rotating an object, for example a line segment around a point and at an angle [which we specify/determine in the pop-up menu], leads to the construction of an image-object that is equal to the original and rotates at an angle equal to the angle we chose to define the rotation.

- Dragging the original object (or image) from a point leads to the transformation of its image so as to maintain the equality of the original and transformed objects and the structural relationship between the elements of their construction (for example the objects remain perpendicular if the angle of rotation is equal to $90^{\circ}$ ).

- Dragging the rotation point leads to the invariability of the properties of the construction elements (for example the objects--the image and the original object--remain equal and vertical if the rotation angle is equal to $90^{\circ}$ ), while the position of the image changes without changing the structural relationship (they remain perpendicular if the angle of rotation is equal to $90^{\circ}$ ).

\subsection{Transformation due to reflection}

Reflection is the transformation of the object with respect to a line of reflection in relation to which the 
transformation takes place. The reflection of an object, for example a segment, with respect to straight line (e), (the axis of symmetry), leads to the construction of an image object which is equal to the original and which has the properties of a hybrid-dynamic object with regard to the construction of its symmetry around the axis.

- Dragging the original object (or its image-object) from one point leads to the transformation of the image (or the original object) so that their equality and the structural relationship between the elements of the construction is preserved (for example the objects - the image and the original object--remain perpendicular if the angle formed by the original object to the axis is equal to $90^{\circ}$ ).

- Dragging the axis of symmetry from a point on it leads to the invariability of the properties of the construction elements (for example, the objects - the image and the original object--remain equal and form the same angle with respect to the axis), while the position of the image changes without changing their structural relationship.

\subsection{Transformation due to the using of action buttons}

5.5.1. Transformation due to the using of hide-show

The construction and use of the action-buttons on the diagram modifies the overall diagram or parts of the diagram on screen, which leads the user to focus on particular elements of the diagram. The gradual appearance of additional elements on the diagram, which is connected to the sequence of the construction, may lead the user to a sequential understanding of the structure due to the reflective visual reaction (RVR) (Patsiomitou, 2010, 2012a, b).

5.5.2. Transformation due to the using of link buttons

It is possible to conceptually link two different software pages on which the diagrams may differ structurally by means of the particular action-button. The use of different link-buttons one after the other helps the user to perceive initially the dynamic section or, later, their logical connection.

\subsection{Transformation due to the using of annotation}

- Use of colors: This action aims to highlight the equal elements of a diagram (equal segments, equal triangles, etc.) with the aim of developing the user's reflective visual reaction (RVR) (Patsiomitou, 2010).

- Use of signs in the angles

- Use of formulations

- The use of a non-permanent trace does not make sense as an individual action, but it does in relation to dragging a point on the diagram (as it forces them to ask: if we drag another point, what will happen?)

\subsection{Transformation due to the using of custom tools}

The custom tool organizes information into an external representation. The subject interacts on the tool through an intermediate representation which relates to its selection from the toolbox. When the tool is first applied, a point is displayed on the screen which, if selected, repeats the construction of the figure we have "condensed" in the form of a command file. As a result of the construction and implementation of the custom tool [as much as the process of iteration] the direct perception of the user is attained in regard to the steps in the development of the construction pertaining to (Patsiomitou, 2007): (1) the repetitions in the measurements or calculations of the areas of initial shapes, (2) the developmental way of the construction of the shape, and (3) its orientation towards the sequential steps of the construction on the screen's diagram or in successive pages of the same file. A script/custom tool combines in a concrete and sequential order the steps that have been used to accomplish the construction. For example, if we construct a square, we can save the concrete construction in a custom tool which can repeat the construction in the concrete way used by the creator of the custom tool, meaning that is processes the objects in the same sequence. The dragging of the custom tool constructed on screen follows the rules that refer to the primitives and commands incorporated into the custom tool (i.e. if we have measured angles or segments, or calculated a ratio, during the construction of the tool, then the concrete measures and calculations are repeated any time we implement the custom tool). If we drag the tool, the measures follow the increasing or decreasing of the length of the segments and angles (e.g., Patsiomitou, 2005, 2007). By constructing a custom tool, we can help students to extend the capacity of their working memory, since the knowledge the student must retain is reduced. Nonetheless, the basic underlying notion is that a student is able to codify a construction and the concrete codification shape what the student can do when s/he will encounter a new situation related to the concrete that has been abstracted and codified with the use of custom tool (See, also Patsiomitou, 2019c, p.79).

\subsection{Transformations due to the synthesis of the diagram}

The diagram is transformed as new elements are added, deleted or removed. The definition of the dynamic geometric transformation in dynamic geometry software based on the visual transformation of the shape with a 
view to gaining perceptual, functional and sequential understanding (Duval, 2002) of the subject, relates to the mental or physical processing or modification of a diagram (Patsiomitou, 2014, pp. 30-31):

Dynamic geometric transformation in dynamic geometry software is any modification to the diagram on screen that brings about a change to one or more geometric objects contained in it. This change may be due to the addition or removal/ subtraction or undoing of elements of the diagram, or because we apply one of the interaction techniques (dragging, tracing, adding animation or motion, measuring or calculating, transforming objects (for example by rotating or reflecting them) or combinations of these techniques. They cause the diagram or parts of the diagram to be transformed or modified or movement, either by reconfiguring the geometric object (for example, by cutting part of the shape and then pasting it elsewhere to make a different equivalent shape) or resizing it (zooming in, zooming out), or even changing its position or orientation.

Constantly changing the diagram through the use of dynamic interaction techniques (Sedig \& Sumner, 2006; Sedig, \& Liang, 2008; Patsiomitou, 2010) leads to a sequence of geometrically variable transformed diagrams. The use of different techniques in the construction of the geometric diagram causes different types of interactions. These interactions thus cause different representations on screen, which in turn lead the students to form different mental representations and to translate these verbally in accordance with how they understand them. The students' mental representations that take shape can bring about corresponding mental transformations which may stimulate a mental experimental transformation in the diagram, even if it is not realized with material means (i.e., the drawings on the software screen), but in the student's imagination. Students are frequently able to predict this transformation on the diagram, because they have associated it with some pre-existing knowledge which they adapt to the particular case.

According to Piaget \& Inhelder (1956), the maturity of the student's thinking plays an important role in helping them reach the mental transformations stage. The challenge was to connect the transformations in static and dynamic means conceptually and procedurally. Instrumental decoding of students' mathematical ideas played a major role for the overcoming of cognitive and instrumental obstacles. This situation aims to accomplish the figure's symbol character. The development of structures in students' minds has been achieved with the synthesis of a more complex construction. The situations aim to develop the abstraction. The design and redesign of activities for the teaching and learning processes, with real problems or simulations of real-world problems through LVAR in the dynamic geometry software, and the results obtained from the research data (Patsiomitou, $2012 \mathrm{a}, \mathrm{b}$ ), suggest that a student develops his/her abstractive competency when his/her cognitive structures are linked through representations that the student develops during the learning process.

\section{Conclusion}

Simon (1995, p. 136) introduced the idea of Mathematics Teaching Cycle and created a diagram in order to represent the way that a learning trajectory is an ongoing modification of three components: "(a) the learning goal that defines the direction, (b) the learning activities and (c) the hypothetical learning process". The analysis of the didactic actions led me in 2014, to the development of the Didactic cycle of Mathematics (e.g., Patsiomitou, 2014, p. 35) adapting the diagram created by Simon (1995, p.136) so that I took into account the use of technology in the mathematics didactic cycle, the modelling of activities with linking visually active representations (LVAR) within the software, and the evaluation of student levels in line with van Hiele's theory. Communication between teacher and students is achieved through mathematical discussions in sequential actions: the implementation of the activities, effective teaching and research into students, exploring what they know, which provides the teacher with the feedback they need to adapt the activities. Moreover, I point out that: (a) The notion of LVAR is directly linked to the notion of instrumental decoding; (b) A dynamic diagram expresses the interdependencies between dynamic objects; (c) A dynamic section expresses the intra-dependencies / interdependencies between dynamic diagrams and mathematical objects (Patsiomitou, 2021).

Learning to use the tools is therefore necessary, but it is just as essential to be familiar with some of the processes that must be followed. It is natural to wonder how much more difficult this process can become within a dynamic geometry software environment, since we also need to learn how to use the software tools. Although it is necessary to learn the tools, things become simpler instead more difficult, since abstract concepts are rendered more and more specific. What is missed from the math textbooks --from the teacher's point of view-- is the configuration of instrumental learning paths using Toulmin models and pseudo- Toulmin models (Patsiomitou, 2021). Then the teacher can, by asking appropriate questions, help his/her students to construct the figure and to relate it to the theory. For example: Which theorem or proposition do you think will help us to construct this figure? What are the steps in the construction process? What tools can we use? Can you construct the same figure using different tools or following different paths? Does the construction differ if we use alternative tools and construction paths?

Because learning "math recipes" is more likely to lead to a behaviorist conception of learning, we investigate how tool interdependencies in an instrumental path can make us "smarter" or "wiser." And geometry 
is anything but "recipes" or "instruction packages", since in order for the process to make sense; the student must connect each construction step with a definition or a relevant theorem: i.e., each step must have a theoretical explanation. This explanation can only be achieved by means of a pseudo-Toulmin model, which analyzes the connections and relationships between dynamic tools and concepts.

"A major goal of having students experience dynamic geometry is for them to gain an understanding of dynamic dependencies. Dynamic dragging can be used to provide a visual acquaintance with behaviors resulting from hidden dependencies. " (Stahl, 2013a, p.81)

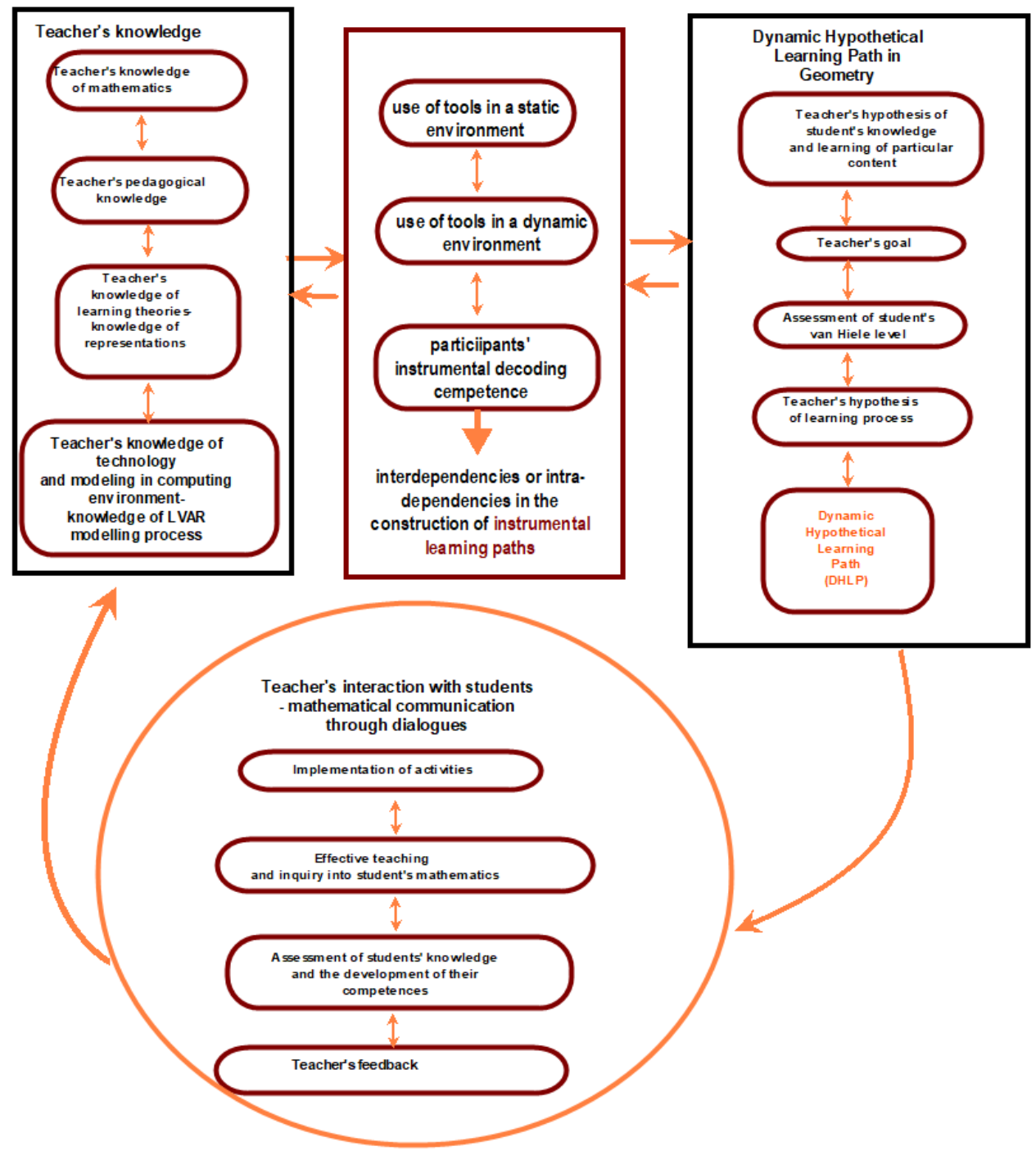

Figure 31. The Didactic Cycle of Mathematics using instrumental learning paths (Patsiomitou, 2021, p. 94)

The whole process got me thinking: how can we provide students with a "journey of knowledge" that is full of experiences through the educational design of the material, when this presupposes that the sequence in which the tools are used is properly designed. The process has to do with the development of conceptual and procedural knowledge on the part of the students and how they can influence each other. What kind of knowledge must be developed first during the teaching and learning of mathematics if students are to understand mathematics? Do students have to learn the concepts before they apply them during processes or vice versa? In my opinion, procedural knowledge can support the conceptual knowledge and vice versa. One of the cognitive aims in my teaching is my students to actively construct the properties of a figure and the connections between them -in other words- to be able to link conceptual and procedural knowledge. This is also the core idea of this research study: the construction of dynamic interdependencies between dynamic objects (or hybrid-dynamic objects) diagrams or sections lies at the heart of the construction of instrumental learning paths. I absolutely agree with Stahl (2013b) who argues that "dependencies lie at the heart of Euclid's geometry, but they have been largely buried in the traditional understanding of geometry" (p.13). Consequently, I complemented the diagram (Figure 31 ), by adding a column in the middle (Patsiomitou, 2021, p. 94). In this column, I note the role of instrumental decoding in a static or dynamic environment, and how the competence of the participants (students -teacher) can 
influence/impact the holistic result of the learning process by creating interdependencies/intra-dependencies during the construction of instrumental learning trajectories.

\section{References}

Argyrakis, D. Bourganas, P., Mentis, K. Tsikopoulou, S. Xrysobergis, M. (2007), Mathematics textbook. O.E.D.B. Athens (in Greek).

Aronson, E., Blaney, N., Cookie, S., Sikes, J., and Snapp, M. (1978). The Jigsaw Classroom. Beverly Hills, Calif.: Sage Publications.

Bodgan, R. C., \& Biklen, S. K. (1998). Qualitative Research in Education. Boston London: Allyn and Bacon, Inc.

Brown, S. (1973). Mathematics and humanistic themes: Sum considerations. Educational Theory,23(3), $191-214$.

Coxford, A. F., Usiskin Z. P.: Geometry: A Transformation Approach, Laidlaw Brothers, Publishers, 1975

De Villiers, M. (1994) The role and function of a hierarchical classification of quadrilaterals, For the Learning of Mathematics, 14(1), 11-18.

Davis, G. E., \& Tall, D. O. (2002). What is a scheme? In D. Tall \& M. Thomas (Eds.), Intelligence, learning and understanding: A tribute to Richard Skemp (pp. 141-160). Flaxton, Queensland: Post Pressed

De Corte, E., Verschaffel, L., \& Greer, B. (2000). Connecting mathematics problem solving to the real world. Proceedings of the International Conference on Mathematics Education into the 21st Century: Mathematics for living (pp 66-73). Amman, Jordan: The National Center for Human Resource Development.

Drijvers, P.H.M:2003, Learning algebra in a computer algebra environment, design research on the understanding of the concept of parameter. Utrecht: CD $\beta$-Press. Ook beschikbaar via www.fi.uu.nl/ pauld/dissertation

Dougiamas, M \& Taylor, P. (2003) Moodle: Using Learning Communities to Create and Open-Source Course Management System, World conference on educational multimedia, hypermedia and telecommunications, 2003 (1), 171-77. http://www.moodle.org.nz

Duval, R. (1995a). Sémiosis et pensée humaine. Berne: Peter Lang

Duval, R. (1995b). Geometrical Pictures: kinds of representation and specific processing. In R. Sutherland and J. Mason (Eds), Exploiting Mental Imagery with Computers in Mathematics Education. Berlin: Springer. pp. 142-157.

Duval, R. (1999). Representation, vision and visualization: Cognitive functions in mathematical thinking. Basic issues for learning. In F. Hitt \& M. Santos (Eds.), Proceedings of the 21st Annual Meeting of the North American Chapter of the International Group for the Psychology of Mathematics Education, Volume 1 (pp. 3-26). Cuernavaca, Morelos, Mexico.

Duval, R. (2002) Representation, Vision and Visualization: cognitive functions in mathematical thinking. Basic Issues for Learning. In F. Hitt (Ed.), Representations and mathematics visualization (pp. 311-336). Mexico: PME-NA-Cinvestav-IPN.

Jackiw, N. Sinclair, N. (2004). Iteration and Dynamic Geometry: Beyond Common Fractals with The Geometer's Sketchpad. Session 142 NCTM Philadelphia

Eisenhardt, M. K. (2002). Building theories from case study research. In A. Huberman \& M. Miles (Eds.), The qualitative researcher's companion (pp. 5-36). Thousand Oaks: Sage Publications

Fangchun Zhu (2020). Teachers' Knowledge for Integrating Dynamic Geometry Software into Mathematics Lessons: contrasting Chinese and French Cases. Education. Université de Lyon; East China normal university (Shanghai).

Fitzpatrick, R. (2007). Euclid's Elements of geometry. Morrisville, NC: Lulu.

Fuys, D., Geddes, D., \& Tischler, R. (Eds). (1984). English translation of selected writings of Dina van HieleGeldof and Pierre M. van Hiele. Brooklyn: Brooklyn College. (ERIC Document Reproduction Service No. ED 287 697).

Glaser, BG., Strauss, Al. (1967). The discovery of grounded theory: Strategies for qualitative research New York: Aldine de Gruyter.

Hadamard, J. (1945). The mathematician's mind: The psychology of invention in the mathematical field. Princeton, NJ: Princeton University Press.

Hershkovitz, R.: 1990, 'Psychological aspects of learning geometry', in P. Nesher and J. Kilpatrick (eds), Mathematics and Cognition, Cambridge University Press, Cambridge

Hiebert, J., \& Lefevre, P. (1986). Conceptual and procedural knowledge in mathematics: An introductory analysis. In J. Hiebert (Ed.), Conceptual and procedural knowledge: The case of mathematics (pp. 1-27). Hillsdale, NJ: Lawrence Erlbaum Associates.

Higginson, W. (2000). Amusing about aesthetics and mathematics. In J. McLoughlin (Ed.), Proceedings of the 2000 annual meeting. Canadian Mathematics Education Study Group, Topic Group A. St. John's, Newfoundland: Memorial University of Newfoundland 
Hohenwarter, M. (2001). GeoGebra [Computer software]. FCR-STEM, Learning Institute, Florida State University.

Jackiw, N. (1991). The Geometer's Sketchpad [Computer Software]. Berkeley, CA: Key Curriculum Press

Jackiw, N. \& Sinclair, N. (2004) Iteration and Dynamic Geometry: Beyond Common Fractals with The Geometer's Sketchpad Session 142 NCTM Philadelphia

Kaput, J. J. (1992). Technology and Mathematics Education. In D. A. Grouws (Ed.), Handbook of research on mathematics teaching and learning (pp. 515-556). New York: Macmillan.

Kemmis, S. \& McTaggart, R. (1982). The action research planner. Geelong, Victoria: Deakin University Press.

Krummheuer, G. (1995). The ethnography of argumentation. In P. Cobb \& H. Bauersfeld (Eds.), The emergence of mathematical meaning: Interaction in classroom cultures (pp. 229-269). Hillsdale, NJ: Lawrence Erlbaum Associates.

Laborde, J. M. (2004). Cabri 3D. Online at: http://www.cabri.com/

Laborde, J-M., Baulac, Y., \& Bellemain, F. (1988) Cabri Géomètre [Software]. Grenoble, France: IMAG-CNRS, Universite Joseph Fourier

Laborde, C. (2005). The hidden role of diagrams in students' construction of meaning in geometry. In J. Kilpatrick, C. Hoyles, O. Shovsmose \& P. Valero (Eds.), Meaning in mathematics education (pp. 159-179). New York: Springer.

Mariotti M.-A. (2000). Introduction to proof: The mediation of a dynamic software environment. Educational Studies in Mathematics, 44(1-3), 25-53.

Monaghan, F. (2000) What difference does it make? Children views of the difference between some quadrilaterals, Educational Studies in Mathematics, 42(2), 179-196.

Olivero, F. and Robutti, O. (2007), Measuring in dynamic geometry environments as a tool for conjecturing and proving International Journal of Computers for Mathematical Learning Volume 12, Number 2

Panaoura, A, Elia, I., Stamboulides, N., Spyrou, P. (2009). Students' structure for the understanding of the axis of reflective symmetry in mathematics. (English) Acta Didactica Universitatis Comenianae. Mathematics, 9 , 41-62.

Patsiomitou, S. (2005). Fractals as a context of comprehension of the meanings of the sequence and the limit in a Dynamic Computer Software environment. Master Thesis. Department of Mathematics. National and Kapodistrian University of Athens. Interuniversity Postgraduate Program. http://www.math.uoa.gr/me/dipl/dipl_patsiomitou.pdf

Patsiomitou, S. (2006a): Dynamic geometry software as a means of investigating - verifying and discovering new relationships of mathematical objects. "Euclid C": Scientific journal of Hellenic Mathematical Society (65), pp. 55-78. (in Greek).

Patsiomitou, S. (2006b): DGS 'custom tools/scripts' as building blocks for the formulation of theorems-in-action, leading to the proving process. Proceedings of the 5th Pan-Hellenic Conference with International Participation "ICT in Education" (HCICTE 2006), pp. 271-278, Thessaloniki, 5-8 October 2006. ISBN 960-88359-3-3 (in Greek). http://www.etpe.gr/custom/pdf/etpe1102.pdf

Patsiomitou, S. (2007) Fractals as a context of comprehension of the meanings of the sequence and the limit in a Dynamic Software environment. Electronic Proceedings of the 8th International Conference on Technology in Mathematics Teaching (ICTMT8) in Hradec Králové (E. Milková, Pavel Prazák, eds.), University of Hradec Králové, ISBN 397-80-7041-285-5

Patsiomitou, S., (2008a). The development of students' geometrical thinking through transformational processes and interaction techniques in a dynamic geometry environment. Issues in Informing Science and Information Technology journal. Vol. 5, pp. 353-393. https://doi.org/10.28945/1015

Patsiomitou, S. (2008b) Linking Visual Active Representations and the van Hiele model of geometrical thinking. Proceedings of the 13th Asian Conference in Technology in Mathematics. pp 163-178. ISBN 978-09821164-1-8. Bangkok, Thailand: Suan Shunanda Rajabhat University. Available on line http://atcm.mathandtech.org/EP2008/papers full/2412008 14999.pdf

Patsiomitou, S. (2008c) Custom tools and the iteration process as the referent point for the construction of meanings in a DGS environment. Proceedings of the 13th Asian Conference in Technology in Mathematics. pp. 179-192. ISBN 978-0-9821164-1-8. Bangkok, Thailand: Suan Shunanda Rajabhat University.

Patsiomitou, S. (2008d). Problem solving through Linking Visual Active Representations in a Dynamic Geometry Software, leading to rigorous proof. Proceedings of the 6th Pan-Hellenic Conference with International Participation "Information and Communication Technologies in Education" (HCICTE 2008), University of Cyprus, pp. 81-88, http://www.etpe.gr/custom/pdf/etpe1232.pdf

Patsiomitou, S. (2010) Building LVAR (Linking Visual Active Representations) modes in a DGS environment. Electronic Journal of Mathematics and Technology (eJMT), pp. 1-25, Issue 1, Vol. 4, February, 2010, ISSN1933-2823.

Patsiomitou, S. (2011) Theoretical dragging: A non-linguistic warrant leading to dynamic propositions. In Ubuz, 
B (Ed.). Proceedings of the 35th Conference of the International Group for the Psychology of Mathematics Education, Vol. 3, pp. 361-368. Ankara, Turkey: PME. ISBN 978-975-429-297-8.

Patsiomitou, S. (2012a). The development of students' geometrical thinking through transformational processes and interaction techniques in a dynamic geometry environment. $\mathrm{PhD}$ thesis. University of Ioannina.

Patsiomitou, S. (2012b) A Linking Visual Active Representation DHLP for student's cognitive development. Global Journal of Computer Science and Technology, Vol. 12 Issue 6, March 2012. pp. 53-81. ISSN 9754350. Available online at: http://computerresearch.org/index.php/computer/article/view/479/479

Patsiomitou, S. (2014). Student's Learning Progression Through Instrumental Decoding of Mathematical Ideas. Global Journal of Computer Science and Technology, Vol. 14 Issue 1, pp. 1-42. Online ISSN: 09754172.http://computerresearch.org/index.php/computer/ article/view/41/41

Patsiomitou, S. (2015). The Open eClass platform as a means for instructional design and curriculum management. Scientific journal "The New Educator (Neos Paidagogos)”. 6th issue, pp.211-244 (in Greek).

Patsiomitou, S. (2018). An 'alive' DGS tool for students' cognitive development. International Journal of Progressive Sciences and Technologies (IJPSAT) ISSN: 2509-0119. Vol. 11 No. 1 October 2018, pp. 35-54. http://ijpsat.ijsht-journals.org/index.php/ijpsat/article/view/636

Patsiomitou, S. (2019a). From Vecten's Theorem to Gamow's Problem: Building an Empirical Classification Model for Sequential Instructional Problems in Geometry. Journal of Education and Practice. Vol.10, No.5, pp.1-23.DOI: 10.7176/JEP/10-5-01.

Patsiomitou, S. (2019b). Hybrid-dynamic objects: DGS environments and conceptual transformations. International Journal for Educational and Vocational Studies. Vol. 1, No. 1, May 2019, pp. 31-46. DOI: https://doi.org/10.29103/ijevs.v1i1.1416.

Patsiomitou, S. (2019c). A Trajectory for the Teaching and Learning of the Didactics of Mathematics [using ICT]: Linking Visual Active Representations. Monograph. Published by Global Journal Incorporated. United States. ISBN: 978-1-7340132-0-7. http://doi.org/10.34257/SPatTrajICT

Patsiomitou, S. (2020a). Didactics, Instruction and Assessment of Mathematics: Learning Trajectories and Curriculum. Monograph. Anatolikos. Athens. ISBN: 978-618-5136-49-9

Patsiomitou, S. (2020b). Didactics and instruction of mathematics: from theory to action using microworlds. Monograph. Angelakis publications. Athens. ISBN: 978-960-616-155-1.

Patsiomitou, S. (2021). Dynamic Euclidean Geometry: pseudo-Toulmin modeling transformations and instrumental learning trajectories. International Institute for Science, Technology and Education (IISTE): EJournals. Journal of Education and Practice. 12 (7). pp. 80-96. DOI: 10.7176/JEP/12-9-09.

Patsiomitou, S., and Emvalotis A. (2010) Students' movement through van Hiele levels in a Dynamic geometry guided reinvention process. Journal of Mathematics and Technology (JMT), ISSN: 2078-0257, 3, pp. 18-48.

Penrose, R. (1974). The role of aesthetic in pure and applied mathematical research. The Institute of Mathematics and its Applications, 7/8(10), 266-271.

Piaget, J., \& Inhelder, B. (1956/1967) The child's conception of space. New York: Norton

Poincaré, H. (1913). The world foundations of science (G. B. Halsted, Trans.). New York: The Science Press.

Rabardel, P. (1995). Les hommes et les technologies, approche cognitive des instruments contemporains. Paris: Armand Colin.

Richter-Gebert, J. and Kortenkamp, U. (1999). User manual of the Interactive Geometry Software Cinderella. Springer-Verlag, Heidelberg

Sang Sook Choi-Koh (1999). A student's learning of geometry using the computer, Journal of Educational Research 92 (1999), pp. 301-311

Scheffler, I. (1965). Conditions of knowledge: An introduction to epistemology and education. Chicago: Scott, Foresman, and Company

Schön, D. A. (1983). The reflective practitioner: How professionals think in action. New York: Basic Books.

Sedig, K., \& Sumner, M. (2006). Characterizing interaction with visual mathematical representations. International Journal of Computers for Mathematical Learning, 11, 1-55. New York: Springer

Sedig, K. and Liang, H. (2008). Learner-information interaction: A macro-level framework characterizing visual cognitive tools. Journal of Interactive Learning Research, 19(1), 147-173

Simon, M. A. (1995). Reconstructing mathematics pedagogy from a constructivist perspective. Journal for Research in Mathematics Education, 26 (2), 114-145.

Simon, M.A. (1996) 'Beyond inductive and deductive reasoning: the search for a sense of knowing', Educational Studies in Mathematics, v.30, 197-210.

Sinclair, N. (2004) "The Roles of the Aesthetic in Mathematical Inquiry", Mathematical Thinking and Learning, Lawrence Erlbaum Associates, Vol. 6, No. 3, pp.261- 284.

Stahl, G. (2013a). "Translating Euclid: Designing a Human-Centered Mathematics." Morgan \& Claypool Publishers.

Stahl, G. (2013b). Translating Euclid: Liberating the cognitive potential of collaborative dynamic geometry. 
Web: http://gerrystahl.net/pub/translating.pdf

Stamatis, E. (1957). Euclid Elements. Books I, II, III, IV. O.E.D.B. Athens

Steketee, S. (2002) Iteration through the math curriculum: Sketchpad 4 does it again and again. NCTM Annual Meeting Session 491

Toulmin, S.E. (1958). The uses of argument. Cambridge: Cambridge University Press.

Trouche, L. (2004). Managing the complexity of the human/machine interaction in computerized learning environments: Guiding students' command process through instrumental orchestrations. International Journal of Computers for Mathematical Learning 9, 281-307. Kluwer Academic Publishers

Usiskin, Z. (1982). Van Hiele levels and achievement in secondary school geometry. Chicago, IL: University of Chicago.

van Hiele, P. M. (1984). 'A child's thought and geometry', in D. Geddes, D. Fuys, and R. Tischler (eds.), English Translation of Selected Writings of Dina van Hiele-Geldof and Pierre M. van Hiele, Research in Science Education (RIE) Program of the National Science Foundation, Grant No. SED 7920640, NSF, Washington, D.C. (Original in 1959).

van Hiele, P. M. (1986). Structure and insight: A theory of mathematics education. Orlando, Florida: Academic Press.

Vergnaud, G. (1998). A Comprehensive Theory of Representation for Mathematics Education. Journal of Mathematical Behavior, 17 (2), 167-181 ISSN 0364-0213

Vinner, S. (1983). Concept definition, concept image and the notion of function. International Journal of Mathematics Education in Science and Technology, 14, (3), 293305 